\title{
HORSES AND MOVEMENT
}

\section{L.D. Luard}




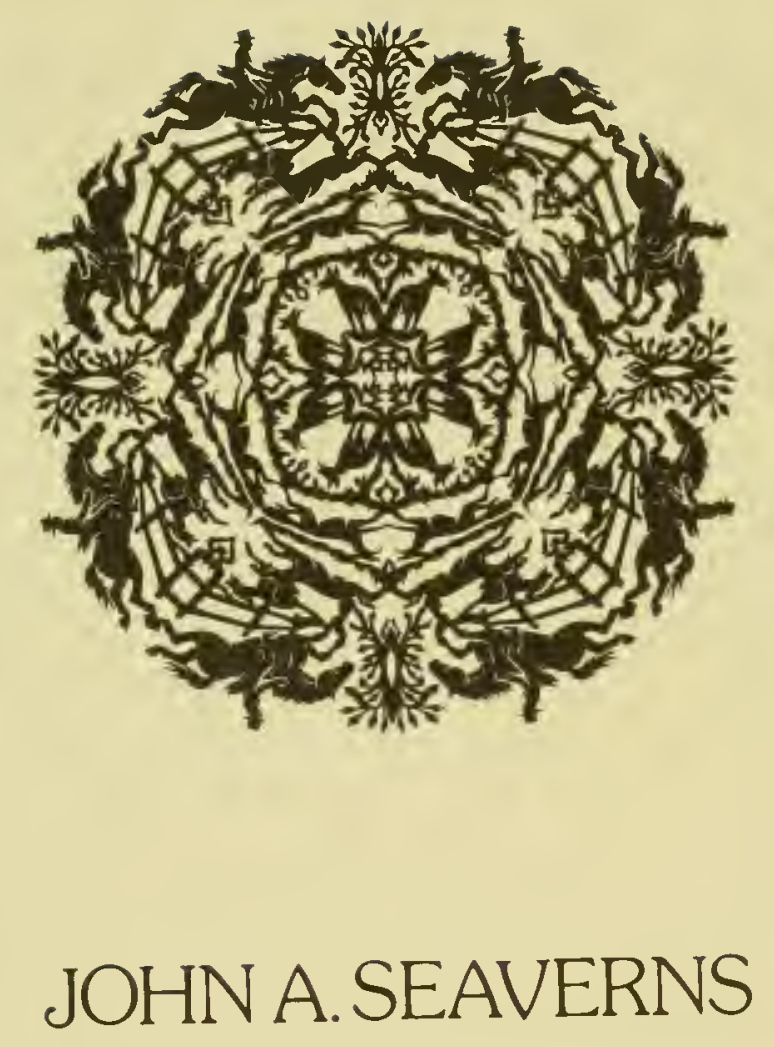




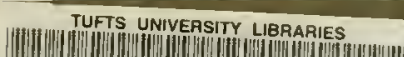

39090014560698

Wekster Family Libren' of Vetennary Medican Cummings Schna' ․ r nary Modkane at

Tui - Lin $\Rightarrow$ sity 200 Westboro Roar North Gratton, MA 01536 
- 


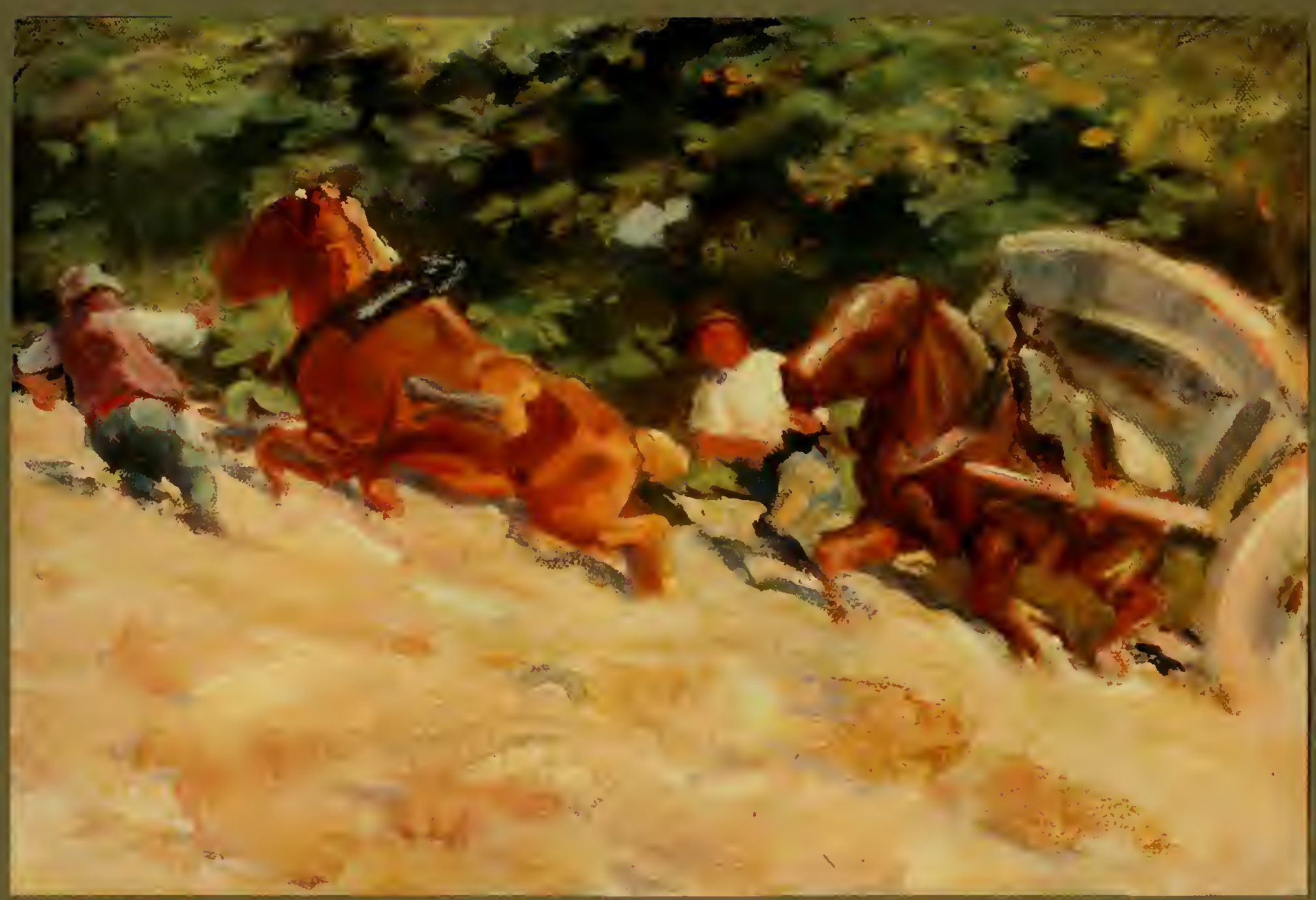

1. CHESTNUT HORSES. (I $6 \times$ IO) 


\section{HORSES AND MOVEMENT}

from PaINTINGS and DRAWINGS by L. D. LUARD With a Note on the Drawing of Movement, by the Artist, and a Foreword by MARTIN HARDIE With Eight Plates in Colour and Twenty-four in Half-tone

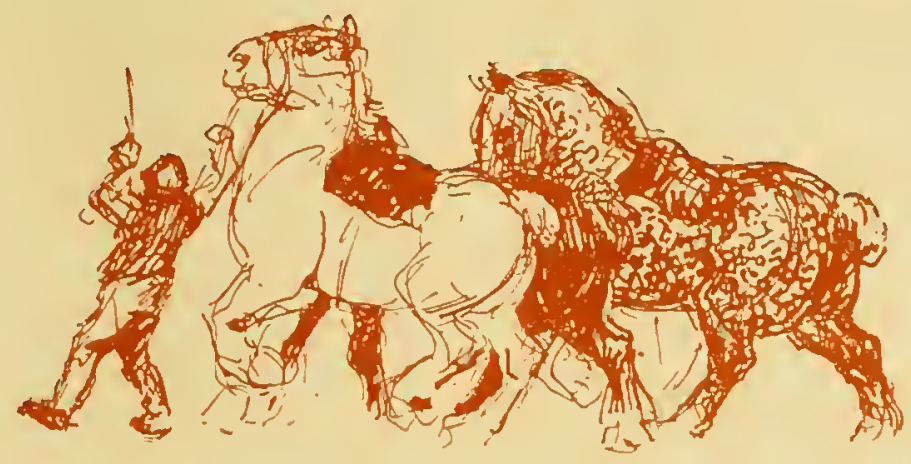

CASSELL AND COMPANY, LTD London, New York, Toronto and Melbourne * * I92 I 



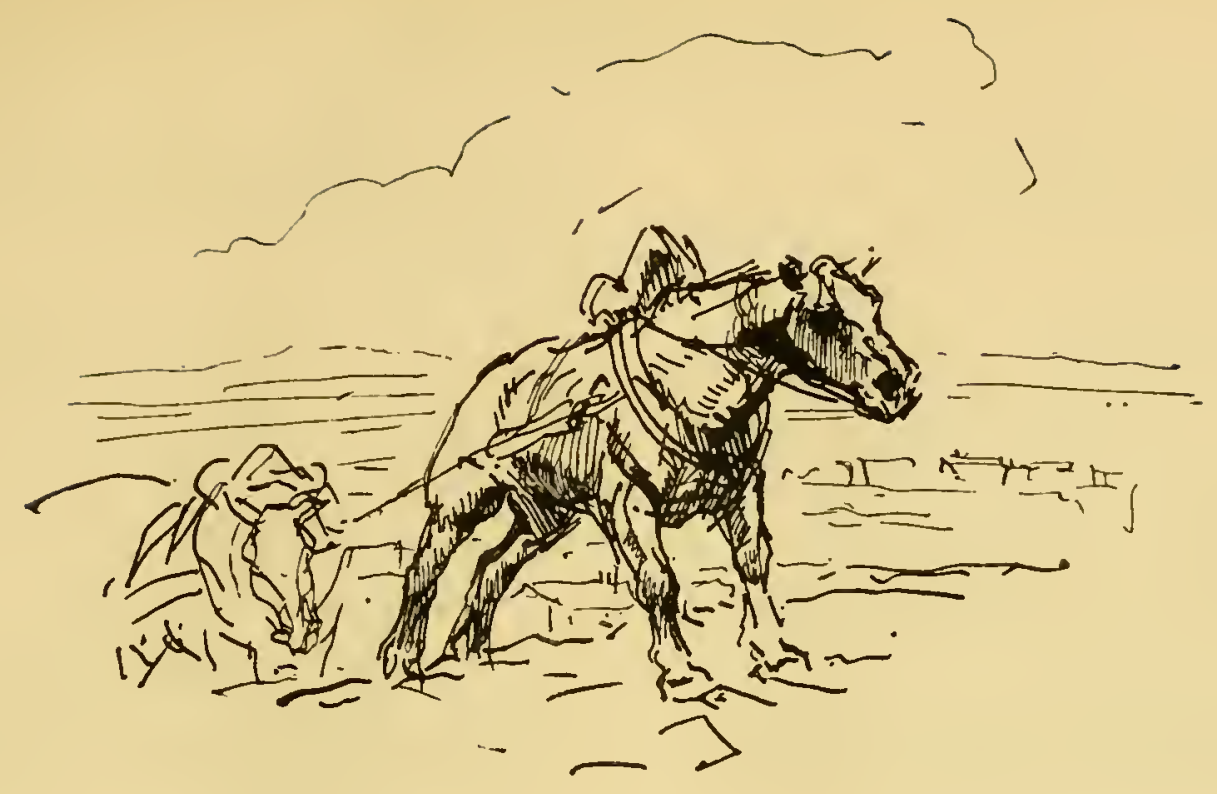

\section{LIST OF PLATES}

I. Chestnut Horses (Colour) Frontispiece

2. Up the Boulevard (Colour)

3. Coup de Collier

4. Tournant le Tombereau

5. Ploughing near Salisbury

6. Charging the Slope (Colour)
7. At Water: Up the Seine

8. Trotting: Paris Bus team

9. Between the Stageș: Paris

IO. ON THE TOP OF THE BANK

II. UNDeR the TREes (Colour)

I2. HARROWING 
I3. UP THE "RAMPE"

I4. Timber-hauling on the Seine

I5. SPRINGING 'EM

I6. A Summer Sky (Colour)

I7. THE SHIRKER

I8. NIGHT WORK

I9. The Black Horse

20. StOne-cart : Bird's Eye View

2I. Turning the Corner: French Stone-cart

22. The Sunny Quay (Colour)

NOTE.-I have to thank Miss Sibyl Maude, Mme. Rotival, Mr. R. A. Blackwell, and Mr. A. H. Macpherson for kindly lending me pictures for reproduction.
23. Led Horses

24. Dead Beat : French Artiliery, the Somme, Igi6

25. AN EFFORT

26. BACKING

27. On the Hill-top near Paris (Colour)

28. FALLEN

29. BLOWN

30. SAND-CARTS

3I. Gun Team in a Crater

32. The Seine: Winter (Colour)

Reproductions Nos. $3,7, \mathrm{IO}_{1}, \mathrm{I} 2, \mathrm{I} 4, \mathrm{I} 7$ and 20 are from photographs by E. Crevaux, of Paris; and Nos. 4, 5, 8, 9, I3, I5 and 25 by S. L. Eavestaff, of London.

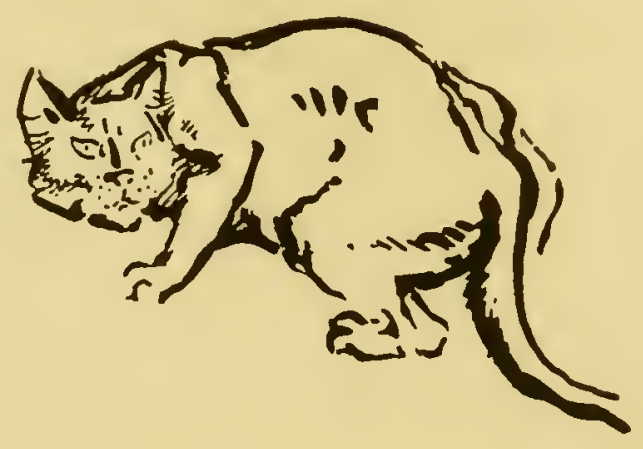




\section{FOREWORD}

7 HE keynote of the paintings and drawings reproduced in this volume is Movement. Work so full of force and originality speaks for itself, but its interest is enhanced by an introductory article in which the artist explains what he maintains to be fundamental principles in the drawing of movement. "The words, Life is Movement," he once remarked in conversation, "should be in capital letters over the studio door." And in a sense it is true, for even the massive and apparently immovable cathedral is obeying the laws of movement, gaining stability as the outcome of the balance of opposing forces thrusting and resisting. In this article Mr. Luard tells us also from a scientific point of view just how we are impressed by movement in nature, though he does not mean to imply that movement in Art needs to include all such impressions.

In his Introduction he speaks with so much authority and writes with so stimulating an appeal to every student of drawing, that one feels that any further preface is superfluous. If, therefore, I have the sense of trespassing on another man's private property, my excuse and justification must be my own admiration of Mr. Luard's work, and the hope that a fairly intimate knowledge of the artist and of his aims and methods may enable me to show how admirably these drawings embody the principles which he upholds. At any rate, it is possible for me to refer more directly to his work than the artist's own modesty would permit, and to emplasize the close relationship between Mr. Luard's theory of drawing movement and his own practice, as illustrated in what I feel to be the remarkable, and in many ways unique, series of paintings and drawings reproduced in this volume.

But first, for the benefit of students who are interested in these drawings, as they surely must be, something should, I

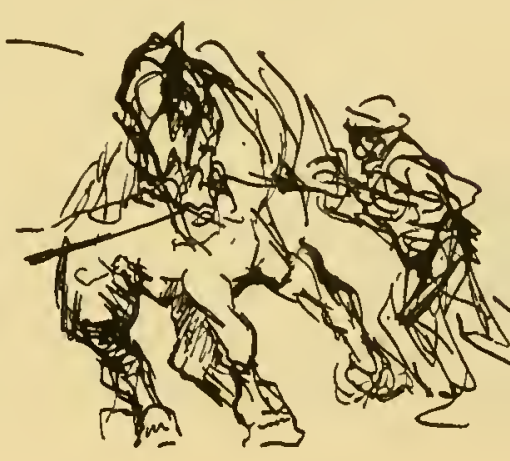


think, be said as to Mr. Luard's own training and career, and I hope that the artist will forgive a critic, who is fully conscious that good wine needs no bush, for playing the showman.

Lowes Dalbiac Luard, as the name shows, belongs to an old Huguenot family of Norman-French origin, and it is interesting to note that one of the capitals in the Abbaye aux Femmes at Caen, from which town the family fled after the Edict of Nantes, was designed and carved by a Luard. It is clear that the family's artistic bent has always been strong and persistent. His grandfather, though a soldier by profession, was also a noteworthy artist. For sufficient testimony we may refer to his "Views of India" and his "Dress of the British Army," and more remarkable still, a series of water colours executed for a diorama of Indian life, which was painted in oils by Louis Haghe and shown at the old "Globe" in Leicester Square, and afterwards in America.

Mr. Luard's uncle, John Luard, also a soldier, became an artist, joined the Pre-Raphaelite movement, and for some time shared a studio with Sir John Millais. One of his Crimean subjects had so great a success at the Academy that it had to be railed off from the crowd. As Colonel Luard, R.E., his father, was also an extremely clever water-colour artist, it is hardly surprising that Art should have claimed Mr. Luard for her own.

Mr. Luard was born in India and educated at Clifton College, where the neighbouring Zoo was an unfailing attraction to a boy keenly interested in drawing living animals. But even before that time movement was his great interest. From the age of five he was constantly drawing horses, always in motion; and family tradition tells how, when only eight years old, he actually lost his dinner one day through following a milkmaid carrying cans on a yoke, keenly alert to watch the balance of her pails and swing of her skirt, of which he afterwards made a complete water-colour drawing from memory. Even at that early age it never occurred to him not to draw a thing just because it was moving.

On leaving Clifton, he worked for a time at a class in Gower Street, conducted by Davis Cooper, son of Abraham Cooper, R.A. Passing to the Slade School, he studied under Professors Brown and Tonks. At the Slade, though he profited by close study of the figure, he was never really stimulated by the posed model. It was when the model rose from the throne, and moved naturally and freely, relaxed his limbs, and stretched his arms, that Luard began to draw with real interest and zest. He was not a School draughtsman. 
His school was the world of real movement outside as recorded in the rapid and concentrated notes and memoranda made from quick observation in his own sketch books.

Though he settled down in London and painted a few successful portraits, it is obvious, from what has already been said, that ordinary forms of laborious portraiture could never be the first interest of such a temperament. In most of his sitters he found little to stimulate his artistic interest; he felt again his instinctive dislike of the posed figure, though with children, who cannot pose, he was often particularly happy. $\mathrm{He}$ felt, rightly, that, as a rule, his first swift sketch in chalk conveyed more of vitality than the finished work in oil.

It was with this feeling that he determined, in IgO4, to follow out a course of drawing in the studios of Paris. He went there intending to stay for three months; he has stayed there ever since. It so happened that soon after he arrived the boulevard opposite to his flat was dug up for repair, and became mouvementé with the going and coming of carts and horses, the lift and heave of figures hammering and digging. Movement, as always, held him at once in thrall, but it was the French draught horse that really kept him in Paris. As he once remarked to me, the horse is interesting because it is the only real nude we can see daily at work. And here on the banks of the Seine, in all weathers and with untiring concentration, he would watch these splendid Percheron horses, which pull as much by energy as by weight, struggling up the steep slopes with their heavy loads of sand and stone. This it was that first inspired the characteristic series of subjects that have held him ever since, and have been shown year after year in his paintings and drawings at the New Salon in Paris, the Goupil Gallery in London, and elsewhere.

Subject and treatment are a matter of temperament. Ingres was all for pure and severe line. Chardin, to take another example, liked to sit and study and contemplate. Most people prefer the static to the dynamic, and Mr. Luard would grant that a picture representative of movement makes many people uneasy. He realizes that movement tends to make a picture restless, and that to many eyes repose has become one of the essential qualities of art. But Mr. Luard does not feel this any more than did such painters as Rubens, Goya or Millet. He can paint a horse in a stable, a lamb browsing among buttercups, and paint them well, and for him they would be interesting studies enough, but unstimulating; and he is right in letting the personal factor overcome 
impersonal facts. Was it Renan who said: "Le plus grand peintre n'aperçoit dans le monde que ce qu'il aime à $y$ voir ; il y a une préférence au fond de chaque talent?" * The painter's problem is not to represent facts, but to express the feeling stirred in him by what he sees. It is not so much the man and the horse that interest

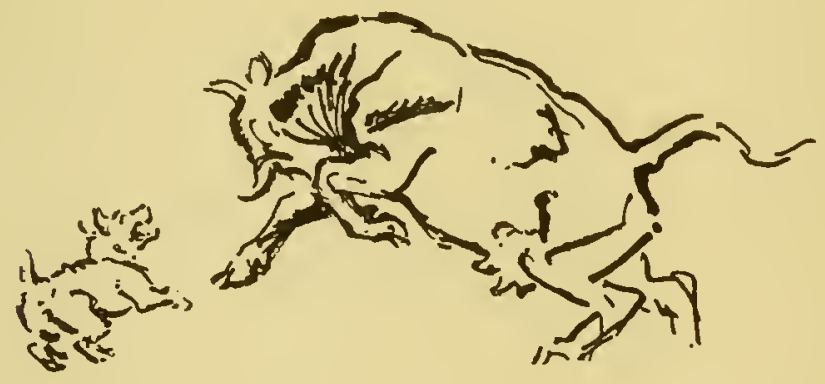

Mr. Luard as the infinite variety of rhythm and music in the toil and struggle that express vitality and life.

The drawing of movement should appear inevitable and spontaneous, like the lyric in poetry. It must convey with rapidity the keen spell of some intense emotion or experience. The draughtsman's work must run to its end with a rush of swift decision, without halt or obstruction, and in its unity it must incorporate and express the

* The really great painter has eyes only for what he wants to see in the world about him. At the root of all true talent there lies an instinctive preference. unity of the experience which inspired it. Being, in this way, the direct result of creative impulse, it must be redhot: it cannot be produced in cold blood. Ingres uses a line that is inevitable in its perfection, but a line which is opposed to the expression of movement. In his case it is an instrument forged and tempered by an artist of cold passion, whose instinctive preference was for patient searching observation, only possible of things at rest, one who from his heart hated the swirling Rubens and all his works.

It follows that the drawing of movement cannot conform to the ordinary rules and principles that circumscribe the drawing of a stationary object, and cannot be judged in the same way. As Mr. Luard indicates, there must be apparent transgressions, approximations, abnormalities. For example, a horse's leg will frequently be more expressive if longer in the drawing than in actual life ; it may be distorted ; it may even be duplicated. In looking at the drawing we must let our mind and eye make the necessary adjustments, just as we make them in looking at nature; and the drawing must be judged, not as a literal rendering of nature, but as a spiritual interpretation of nature's facts. It will be noticed, for instance, that Mr. Luard is sometimes so keenly interested in the larger problems of his work that he 
ignores the smaller facts. He may omit altogether a horse's harness or headpiece, or all those petty details on which the camera insists. Yet he summarizes so boldly for the eye that I think, in most cases, such omissions pass unnoticed, as they do in nature, where the movement is the real interest. He gives things which the camera picture cannot express, for with the camera there can be no selection, no emphasis, no accentuation of the important or suppression of the unimportantin a word, none of the emotion that is naturally necessary in the exercise of an activity which is an emotional language. And when you come to study and analyse drawings of movement such as those in this volume, you must understand that nearly all are drawn from memory. You will realize, after a moment's thought, that movement can only be drawn from memory. Millet, for instance, painted largely from memory, depending entirely on a highly-trained receptiveness of the eye, which enabled him to select with absolute fearlessness and to generalize with absolute knowledge. His observation was undisturbed by the kaleidoscopic shifting of the pictorial elements which bewilder the piscemeal painter. Millet, to quote Mr. Sickert, " did not say to the woman at the wash-tub, 'Do as if you were washing, and stay like that for four or five hours, while
I paint a picture from you,' or to the reaper, 'Stay like that with the scythe drawn back, pretending to reap.'

'La Nature ne pose pas,' to quote his own words. He knew that if figures in movement were to be painted so as to be convincing, it must be by a process of cumulative observation."

That is how Mr. Luard has worked, and you will find in these pictures that he is interested in the beauty of weight as well as of energy. He realizes that in drawing movement the artist will run into excessive and empty rhythm, as is sometimes the case with Japanese art, unless he expresses the downward thrust, as well as the horizontal lines of motion. In drawing a plunging cart-horse he suggests always its weight as well as its movement. Among the painters whom he admires are those with the plastic sense-Rubens, Millet, Daumier.

I have written in general terms of the principles of Mr. Luard's work, because I prefer to leave the separate drawings to speak for themselves. But to show how the qualities of Mr. Luard's work strike another observer, I should like to quote from a criticism by Sir Claude Phillips, in the Daily Telegraph, of one of Mr. Luard's exhibitions in London:

"An all-important quality which Mr. Luard possesses in a high degree is that of expressing at one and the same 
time momentariness, dynamic force at its highest, and solidity, weightiness, permanence. Mr. Luard's great triumph is in his black-and-white drawings and pastel studies of cart-horses in violent action. With delight in their power and his, he renders these great splendid beasts of burden, momentarily rebellious against the domination of man, rearing, plunging, threatening-in their might the Titans of the fields-yet soon to be brought into line again by the whip and voice of the conqueror. The men and the beasts are obviously French, and studied in France, but the treatment is quite original and of singular power. We are not able for the moment to cite any modern artist who with such tremendous force, and withal such accuracy, has delineated horses of this type in moments of fury and terror, when individual struggle takes the place of combined and harmonious labour. . . . Truly a Millet in actiona Millet to which an electric battery has been applied."

Though this volume deals primarily with movement as a leading aspect of Mr. Luard's art, it must not be forgotten that his work has qualities of tone and colour that must not be overlooked. Though most of the reproductions are from drawings in monochrome, several are from paintings; and while movement is the keynote of the pictures reproduced, they also possess sterling qualities that depend on sensitiveness of colour vision. One may note in this connexion the feeling of space and air that surrounds the horses and figures in "Ploughing," "Tournant le Tombereau" and "Horses at Water"; and the sense of Notan, as the Japanese call the use of dark and light pattern for emotional effect, which is so effectively used in "On the top of the Bank" and "Between the Stages." Here, and elsewhere, Mr. Luard's colour is quiet and good; and it is noteworthy that he sees and uses it mostly in quiet scenes. This is perhaps due to the fact that in Paris and in England colour very rarely rises to an emphasis and violence which is sympathetic and lielpful to the expression of vigorous movement.

This volume is intended largely for the student, and on that account I feel constrained to utter a word of warning. These drawings, sometimes so slight, are seemingly so spontaneous and inevitable-so easy and rapid in execution-that the young student may think that he can begin where they end. Looking at one of them he may say that it took five minutes or less to make, but Mr. Luard would have the right to reply, like a distinguished predecessor, "It took me a lifetime." The lesson to the student should be that he must look and look and look, training his memory, and storing 
knowledge, just as electrical power is generated and stored. Turner is perhaps the great instance of this memorizing power. He has been proved to have incorporated from memory in his later pictures facts of nature used and recorded by him in drawings that he had made twenty years before and never seen again. And so the student who is drawing, say, a moving horse must seek, unconsciously, in the stores of his memory, and must be able without further thinking-when seeing a new movement he has no time to think-to set down the turn of knee or pastern, the twist or tautness of a muscle. Do not run away with the idea that no drudgery is needed too as grammar, or that Mr. Luard is unable to draw with untiring precision as well as untiring observation. He has a whole volume, which I have seen, embodying his own studies of anatomy and recording not only most precise details of bone, muscle and sinew, but the sheer mechanics of their pull and play. Without this also these drawings could never have been made. The importance of study, of memory, and of knowledge, which is memory stored, is so great, particularly where movement is concerned, that I should like to close with a quotation from Mr. Clausen's "Lectures on Painting." "Some years ago," he writes, "that great artist, Mr. Watts, was good enough to give me some advice. I was speaking of the difficulty of doing something I was trying to do, because I could not get a model to pose, and I said, 'Of course, one has to rely on memory.' 'Yes,' he said, ' memory is a good thing, but there's a better. I asked what that was. 'Knowledge,' he said."

Martin Hardie.

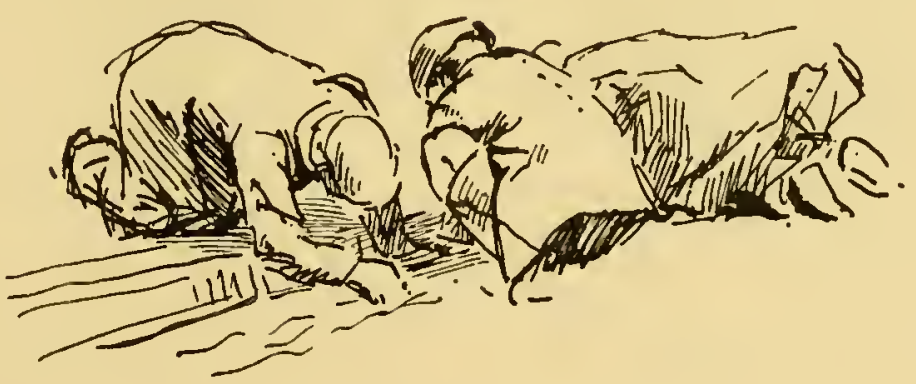




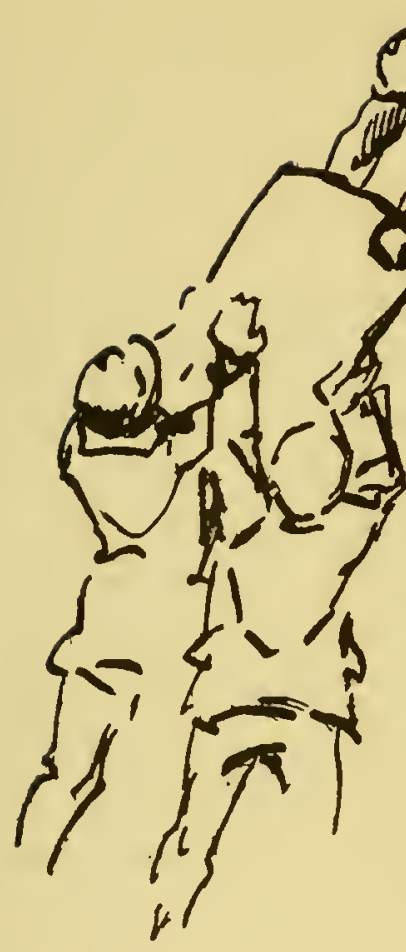

\section{ARTIST'S NOTE}

THE pictures in this book were in no sense done as illustrations to the text. They were selected from the drawings and paintings of recent years, when the publishers proposed to issue a book of reproductions of my work. The Note on the Drawing of Movement was written subsequently at their special request.

Any theories advanced in it are derived empirically from practice, and have never been allowed consciously to interfere with feeling and instinct in production.

It is the outcome of the musings of an artist and is meant for those who are interested.

L. D. L. 


\section{A NOTE ON THE DRAWING OF MOVEMENT}

A

NYONE who has watched a greyhound running must feel that the undulations of the animal, with their rhythmic series and culminating accents, are comparable to the run and rhythm of an air in music, whereas a momentary phase of the movement, such as is recorded in an instantaneous photograph, resembles a detached chord, and, like it, has little meaning out of its context.

Why is it that the instantaneous photograph almost invariably fails to capture any of this rhythmic sensation, or to recreate enjoyment such as is experienced in watching the greyhound run, whereas certain pictures successfully do so?

Is it not because our sense of movement is a subjective impression with which consequently the artist alone can deal?

While most people enjoy watching, shall we say, dancing, very few of them seem truly to be conscious of the source of their enjoyment. The majority appear to be unaware that their pleasure lies in following the visible music of motion, not in observing the dancers, who are only the instruments by which it is performed. As a result they are willing to accept as a picture of dancing a lifeless picture of dancers, which no more recalls the rhythms that were the essence of their pleasure than a picture of a violinist with his bow upon the strings revives the sounds that he was making.

How then is the artist to capture this emanation, at once so real and so transitory?

Perception of movement is the result of combining mentally a series of separate impressions.

In consequence our perception of movement is a subjective impression, so that in making a drawing of a moving figure or object there can be no question of copying the movement, no question of accuracy in the ordinary sense in which it is applied to the drawing of objects at rest. This is a point of capital importance, although apparently very few people, 
even of those really interested in Art, have troubled to consider it.

Movement implies change, and our perception of movement depends upon noting and comparing changes

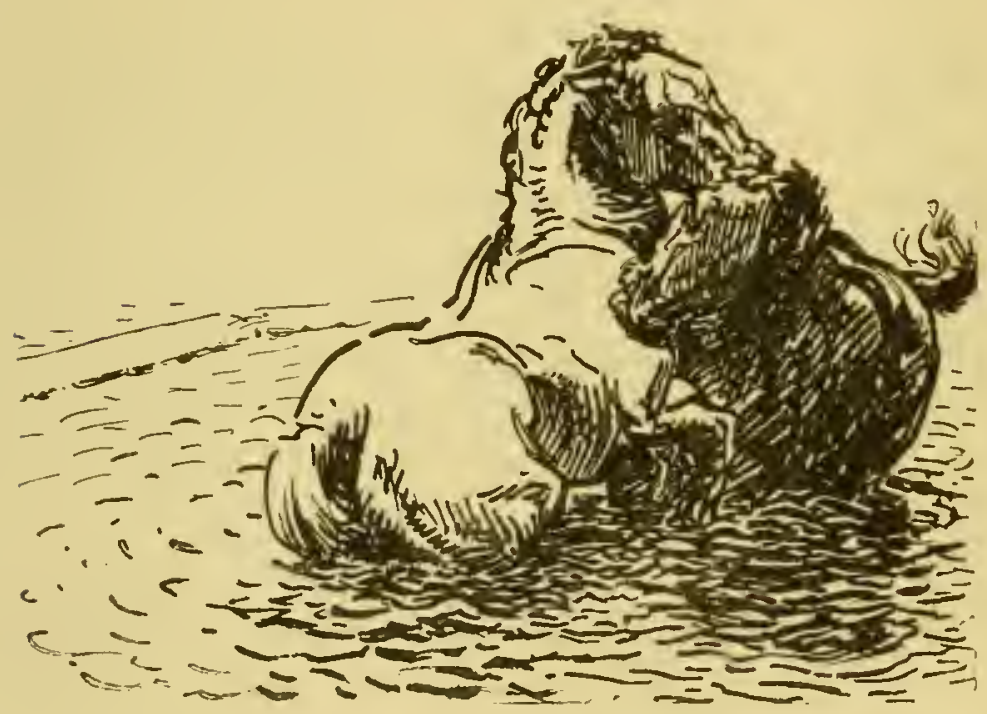

of shape, tone or colour in a series of visual impressions, just as our sense of music depends upon the comparison of a series of momentary sounds.

If sensation did not endure after the stimulus that created it has ceased, we should be incapable of perceiving change, and we should be sensible only of the impression of the actual moment, disconnected from all that comes before or after, seeing, like the photographic plate, only the separate attitudes of which the movement is composed, and never receiving the generalized impression which means seeing movement.

Our perception of movement, then, is created by an act of recollection and is dependent on memory. Consequently it can only be drawn from recollection.

In this the drawing of movement differs essentially from other forms of memory work. Artists, of course, constantly work from memory when dealing with fugitive effects of light, colour, grouping. They do so because such effects, though stationary, are of such brief duration that they do not allow sufficient time in which to record them on the spot. A group of figures, for instance, if only it would remain unaltered for a considerable length of time, could be painted directly, as the still-life painter paints his subjects, but the artist knows from experience that the group may at any moment be broken up by the movement of the individuals that compose it, so that he may think it wiser, instead of spending any of the precious seconds on the act of drawing, to devote them all to observing and storing up an impression from which he can work later.

In such a case, to work from memory is merely the 


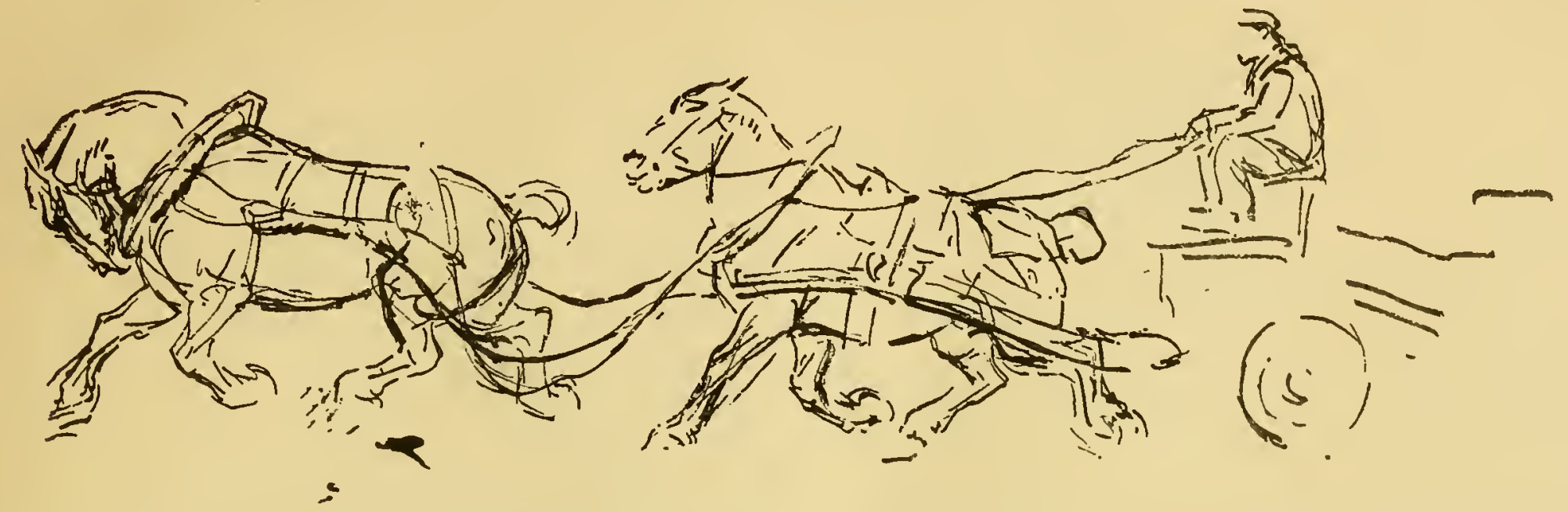

most practical way of working, whereas in the case of drawing movement the artist must work from memory, because he has no choice. For the movement which was the subject that roused his interest is only perceived as an idea formed in his mind out of impressions of phenomena which have already disappeared; just as the idea of an air in music is formed of impressions preserved of sounds that are no longer heard. His subject, then, is not like a fugitive effect, which, however short its duration, is in principle stationary, being formed of parts simultaneously present, and so simultaneously to be observed. For his subject is an idea formed of impressions of successive phases which cannot be received simultaneously, and consequently can only be combined through recollection.

Instantancous photography is to many people a great obstacle to the proper understanding of how we perceive movement and what is involved in expressing it. The camera analyses and records for us passing phases of action which the eye cannot perceive, but which can be proved to occur; and being an unemotional machine free from the frailties of excitable human beings such as artists, in general opinion it " cannot lie." Many people therefore prefer what the camera offers them to what they are offered by their own senses, and in time even come to believe that they ought to see 
as the camera sees. This is manifestly wrong, for, as has already been said, the camera cannot record movement. It never sees it. It arrests the effect of a moment, selecting instantaneous aspects only, thus producing a stationary condition which is the negation of movement itself.

"But photography does produce a vivid sense of movement," the reader will perhaps exclaim. "Look at the cinematograph!" Exactly-the cinematograph is the best proof of the camera's incapacity. For since a single photograph cannot, like a drawing, express movement of itself, the cinematograph is compelled to use them by hundreds, projecting their images in rapid sequence on the screen so that the eye may actually follow their variations across its surface through a period of time. The cinematograph does not attempt to summarize impressions of movement as the artist must. It expresses like by like, creating a fresh series of varying impressions which are reminiscent of the original impressions of the living scene from which the films were taken, reviving in their sequence the actual rhythms, obscurities, indefiniteness, distortions and emphasis of certain things which we should have seen for ourselves in nature. For if properly controlled it hides the camera's records of the stiff momentary attitudes invisible to us through which the limbs of the dancer or the greyhound pass, by merging them in the graceful rhythms which result therefrom, just as in nature the actual attitudes are hidden in the grace of the dancer and the greyhound.

Art cannot use movement to represent movement. It has to render it in the fixed and unchanging materials in which the painter or the sculptor works, and in which indeed lies his strength. For the artist's purpose is not to reconstruct nature, but to communicate his own emotion and interest to others, whether his art be realistic and imitative or an abstraction not recognizably connected with natural appearance.

If it is the representation of movement that the artist attempts, his task at first sight appears similar to the summing-up of an air in music in a single chord. This comparison is hardly fair, however, for the eye of the spectator who is looking at a work of art does not embrace the whole at once, staring fixedly at one central point, but travels about its surface, so that the artist has a considerable area at his disposal over which he can lead the spectator's eye in such a manner as to produce the desired effect upon him. The quotation from Rodin, given further on, in which he explains how the eye is led across his statue is a good instance of this principle. 


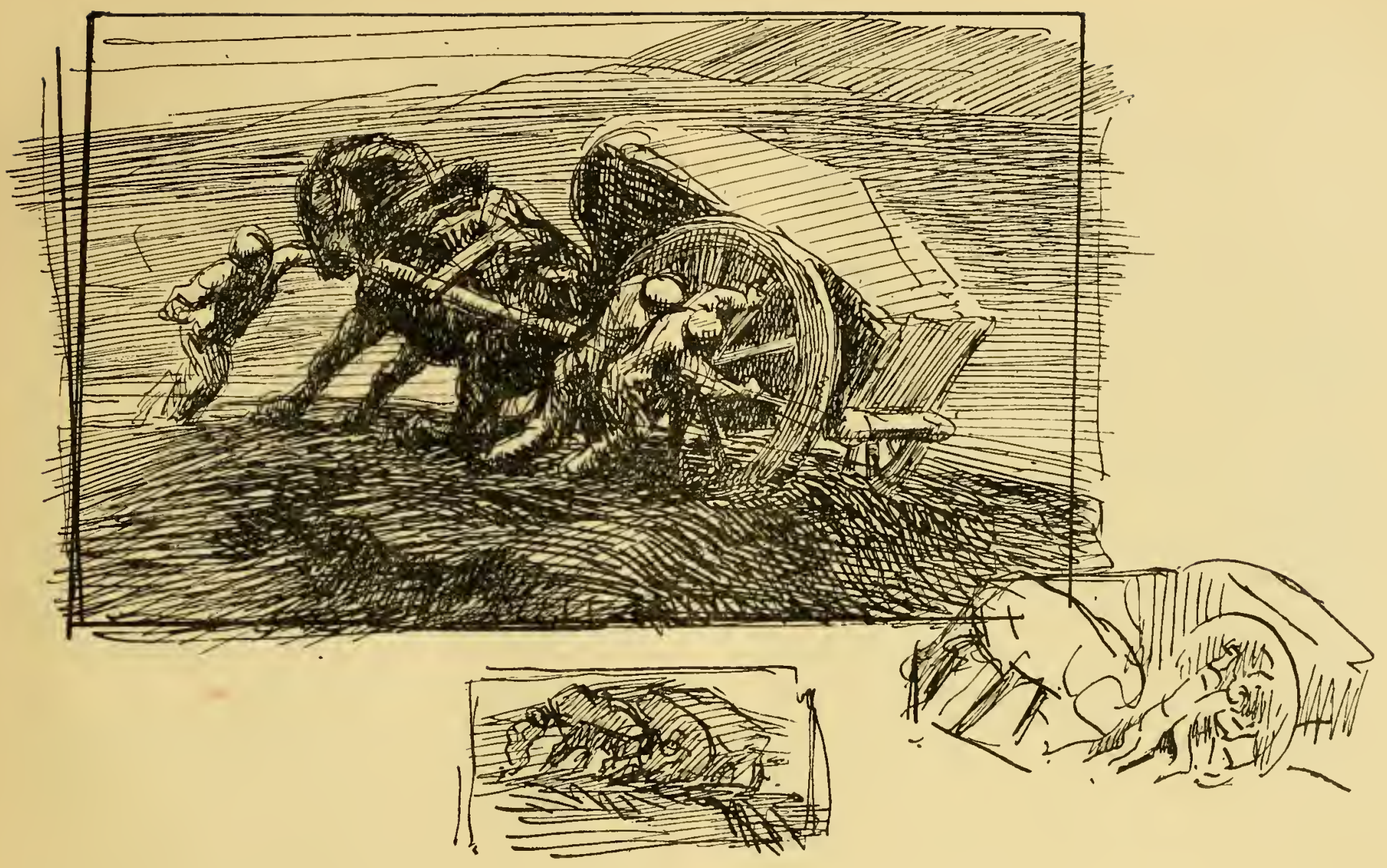

C 
Movement is primarily perceived as direction. Picture to yourself a wet day, and instinctively you will represent the falling rain as making lines across the landscape. In an instantaneous photograph of such a scene the foreground raindrops, if sufficiently distinct, would be shown as separate drops dotted about upon it. Which is the more satisfactory representation? Which gives the "truth"? Which brings about in the mind of the spectator the necessary optical condition? The answer is without doubt: and it is an answer endorsed by the cinematograph, which would be unable to show us movement if it did not restore such generalized impressions which are not to be found in its separate photographs.

The lines of falling rain illustrate a principle that affects all our perception of movement. If we return for a moment to the definition of our perception of movement as a perception of change-of change of position (change of shape is merely change of position of component parts)-we shall agree, I think, that there can be no impression of movement which does not imply a perception of its direction. And direction can be best expressed diagrammatically by a line or lines. What, in fact, are the lines of falling rain but nature's diagrams, the paths of the raindrops traced by faint images of themselves?
But there is something more involved than mere movement and direction. Whatever instances we takethe curves of a swallow's flight, the appearance of a circle created by a thing whirled rapidly about a centre, the undulations of the coursing greyhound, the movements of a group of dancers, the effort of a cart-horse-we find in each of them the same principle, that all movement is not only perceived more or less distinctly by its lines of direction, but also nearly always gives rise to rhythm.

Consequently if the artist is to create in the mind of the observer the desired optical condition he must succeed in reviving and conveying to him his impressions of the original rhythm. Throughout all art it is to be observed that motion is in fact expressed in this way, through the designing of patterns such that the eye of the spectator will travel across them slowly or rapidly, regularly or variably, continuously or interruptedly, as the artist intends, and as he feels the expression of the particular effect or emotion requires.

Such patterns can be so irregular and so interrupted that it may seem hardly fair to call them rhythmic. But I think we may again turn to music for comparison. For in music the movement of a piece may also be so. irregular and interrupted that the word rhythmic is hardly to be applied to it. Yet in both cases if there is 
not to be a complete disconnexion of parts, there must be a sense of continuity which carries across the interruptions and re-establishes the rhythmic principle.

The comparison may be challenged on the grounds that the rhythm of music occurs in time, which it may be said does not find a place in looking at a work of art, of which the whole is seen simultaneously. Such an argument is based on a misunderstanding of how pictures and statues are really seen. Even a general impression of a picture is only received by a survey, however rapid. And really to see and grasp all that is in a great picture is a task equivalent to grasping all that there is in a great play. The mere act of running the eye along any of the innumerable paths of a picture involves an expenditure of time, however brief, which shows that the sense of rhythm conveyed by works of art is as truly dependent upon time as is the rhythm of a piece of music.

Motion which does not give rise to rhythmic impressions seems to be beyond the essential powers of art to express, and the occurrence of such motion can only be suggested by the representation of certain phenomena from which it can be deduced by a process of reasoning. A railway train at speed shows no changes of shape, and creates no rhythmic impressions, thus giving to the artist no means of appealing to the spectator's natural response to rhythmic suggestion. He may blur the spokes, and from such an indication the spectator may reason that the train is in motion; but he does not feel it. Allow the artist, however, to build a pattern about it, of trailing steam, flapping window blind, and whirling paper picked up from the track, or still less connected with the train's motion let him throw a rhythmic pattern of tree-shadows upon train and embankment, and he can produce a feeling of swift movement in the picture, despite the train's own inexpressive rigidity.

The representation of phases and phenomena associated with our perception of movement in nature such, for instance, as indistinctness, confusion, apparent deformation, though it may intensify and complete the effect created by the fundamental rliythms, is ahways subordinate to them. For while a mere pattern dissociated from all idea of nature, and all representation of objects, can produce an effect of motion to the eye, a figure represented in a picture, however clearly it is shown to be in action, will produce no such effect if it does not make a pattern or form part of a pattern which is rhythmic in itself; and this, as has been already pointed out, the arrested attitude of a figure as recorded by an instantaneous photograph hardly ever does. 
There is a picture by a well-known artist which illustrates the point exactly. The subject is a group of figures dragging a heavy load. Their attitudes, however, combine into a pattern of which the rhythmic flow is backwards in opposition to the intended forward motion. As a result there is created in the mind of anyone who is sensitive to rhythmic design, a strong impression that they are moving backwards, despite their attitudes. One can reason that they should be advancing, one feels the contrary. Such a contradiction makes nonsense and is

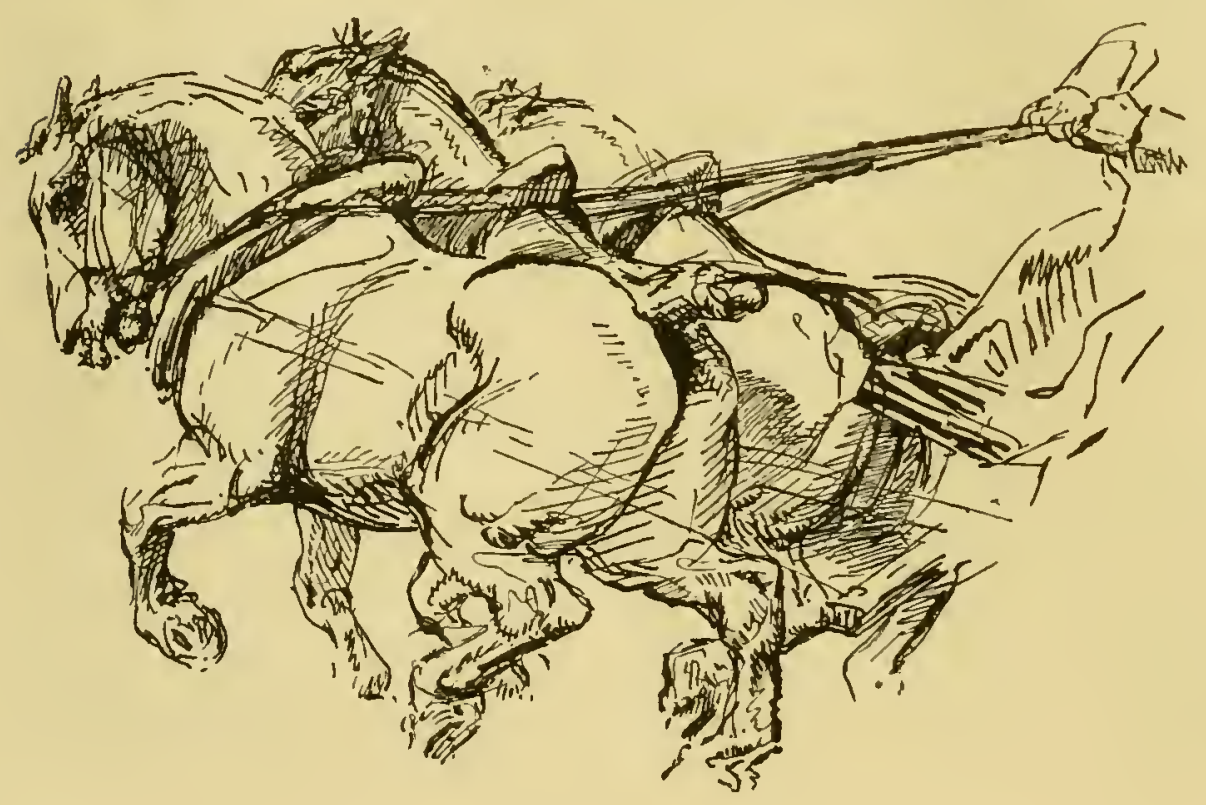

untrue to what we see, for in nature, where things actually move, it could not possibly occur.

Whistler on a certain occasion, after studying deeply the border of a Japanese mat, exclaimed that its design had revealed to him how to express motion by pattern. Although, when a movement is so regular as to be expressed diagrammatically as a straight line or a circle, there is notling in such lines to suggest that there is flow in either direction, yet patterns can be so designed that the spectator's eye is irresistibly led across them in the intended direction and at the intended speed. When inventing such patterns the artist resembles the author, who so constructs his passages that he compels the reader to read them fast or slowly, smoothly or abruptly, according to the particular feeling he wishes to arouse.

Good illustrations of this principle are to be met with everywhere, for instance in the ornamental borders of books, or ancient Chinese bas-reliefs, where figures, plants and patterns flow into each other, leading the eye along the mere patterns with the same sense of motion that it feels in looking at the running figures. Or test the effect of pattern by taking some turbulent picture by Rubens or Goya, or a 
quieter subject by Botticelli or Watteau, and looking at them upside down. You will soon see if the rhythms are expressive. For by so doing you will be less able to see what the figures are about, or to reason out the action of the picture, and you will be more directly affected by the design, so as readily to detect the shortcomings of the group of pulling figures in the picture first instanced, and to enjoy more consciously and fully the effect of great work. To take two pictures by Rubens, you will notice how in the "Country Dance" in the Prado Gallery the background contributes to the action of the figures, how the trees and landscape forms dance and turn in sympathy with the group of dancers, and how in his "Lion Hunt" at Munich the shapes made by the shields, plumes, horses' tails and all add to the savageness of the struggle.

You may also notice in his more violent pictures low little the parts are allowed to hold your attention : that though the details of the heads and other parts are to be found, if you look for them, they are skilfully subordinated so as not to arrest your eye for long from following the swirling pattern. Is not this again a truth to nature? For when looking on at such a scene we should be watching the action, not noticing details of the actors.
How far the underlying basic rhythms of such pictures resemble nature's rhythms it would be difficult to determine. Yet we are often struck by the vividness and exactness with which some lively sketch recalls a natural movement.

Artists must vary as much in their perception of movement as they do in that of colour, tone or form. Some must have quicker eyes than others. The normal eye requires, $I$ think, fourteen films to the second in the cinematograph if it is not to notice any interruption in the continuity of the picture on the screen, though the required number varies with the intensity of the light. Both quick and slow eyes see no doubt beanty and interest invisible to each other. Every artist, then, has a different problem, and must discover for himself how to convey his impression. He must rely upon his own firsthand observation interfered with as little as possible by the vision of others, or the vision of the camera.

The following quotation from a conversation with Rodin, given in "L'Art" by Gsell, bears directly upon this question of how the observer's eye is led about a work of art, and shows how admittedly conscious an artist can be of the influence of such principles in his own work. "It is possible," said Rodin, "for a sculptor to create the illusion that the muscles of his statues really 
move by not representing every part of the figure at the same instant of time. . . . In the statue before you, for instance, the legs, the hips, the body, the head, the arms are given, not at the same moment, but at intervals of moments. I am applying no theory here, I am following an instinct which leads me to express movement in this way. As a result, when the spectator sweeps his eyes from one end of my statues to the other, he sees their gestures grow. He follows the muscular effort across the different sections of the figure from its slow inception to where it culminates."

We may notice particularly that Rodin declares that such a method is instinctive, although he is able to analyse the cause of his success in rendering the movement.

Rodin insisted very strongly upon the necessity of studying the model in motion. For whatever study is made of the posed model, it must never be allowed to supplant or to obscure the impression derived from the moving figure. He used to point out that the swing of one side of the body is only possible because of the movement of the other side. It is the observation of this principle, he declared, which makes his St. John walking and not posing. It is impossible for a model to " take the pose " of a man walking, quiet as the movement is.
The forward inclination of the body of a man running cannot be imitated by a posed model. For in running the impetus is in itself a support to the body. He used as an obvious illustration of the falseness of the "posing of a movement" the case of a man hammering. So long as he holds the hammer in "the pose " he is contradicting the sense of it all. He is contracting the muscles which prevent the arm and hammer falling, and relaxing those which should be pulling it down.

Truisms? Yes, but truisms too often neglected in art because obscured or lost in the exclusive, or almost exclusive, study of the posing model. Yet we all know that if we receive a violent push on the shoulder we inevitably slew round, because one side of us is, so to speak, walking forward more rapidly than the other. The model posing is as true an example of this law of the interdependence of parts as a man in action. For it is only by keeping the right side of his body still that he can keep his left side unmoved also.

If an artist is content to accept the pose of the model as a substitute for the observation of natural movement, the better he draws the more completely will he defeat himself-for the better he draws the more perfectly does he express the model's immobility.

Rodin's analysis of how the impression of movement 
in his statues is created is, I am afraid, not much of a working rule, applied as such. Is it not rather one of the rules to which Sir Joshua Reynolds refers in his Sixth Discourse? "The rules by which men of extraordinary parts, and such as are called men of Genius, work, are either such as they discover by their own peculiar observations, or are of such a nice texture as not easily to admit being expressed in words ... Unsubstantial, however, as these rules may seem, and difficult as it may be to convey them in writing, they are still seen and felt in the mind of the artist; and he works from them witl as much certainty as if they were embodied, as I may say, upon paper. It is true, these refined principles cannot be always made palpable, like the more gross rules of art; yet it does not follow, but that the mind may be put in such a train that it shall perceive, by a kind of scientific sense, that propriety which words, particularly words of unpractised writers, such as we are, can but very feebly suggest."

What, then, can we discover "by a kind of scientific sense " from Rodin? Confidently to give play, I think, to our instinctive preferences when in front of nature, allowing lier to disclose to us what she will, and to try through the study of successful effects, both our own and others, to discover the cause of their effectiveness.
For as Reynolds says earlier in the passage from which I have already quoted, "It must of necessity be, that even works of Genius, like every other effect, as they must have their cause, must likewise have their rules: it cannot be by chance that excellencies are produced with any constancy or any certainty, for this is not the nature of chance." The proper manner of such inquiry is given by Browning in a letter of advice upon the work of a young poet, in which he tells him to "study the secret of the effectiveness, whatever poetry does affect him-not repeating, or copying those effects-but finding out, I mean, why they prove to be effects, and so learning to become similarly effective."

I have attempted something of the sort in this article, and I hope that it may help to the better understanding of the work of certain men, by showing that there is reason for and truth in the effects that they employ. I think also that our attempts at analysis should encourage the artist. If there is a reasonable-

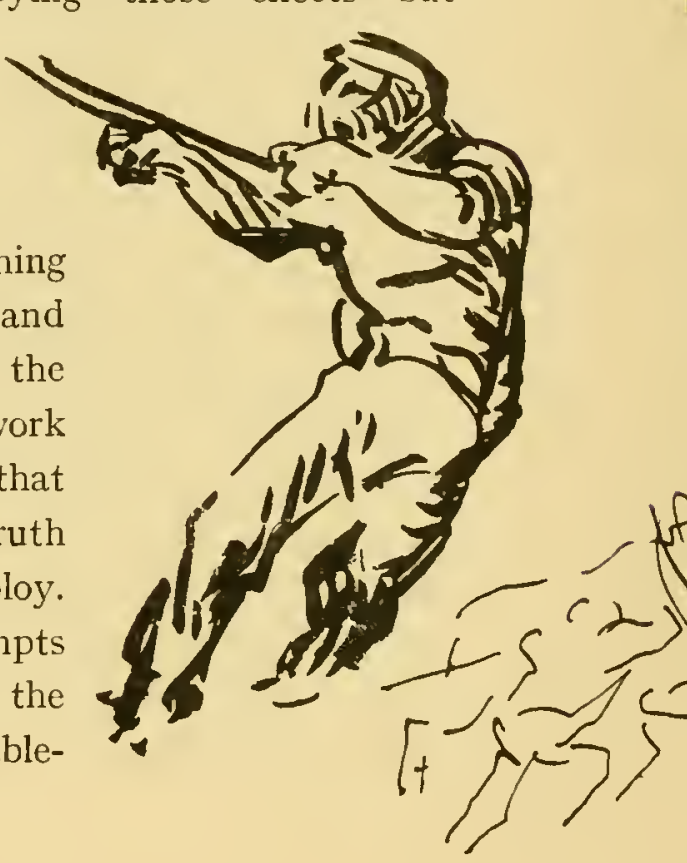


ness behind the effects we have been discussing, why should there not be an equal reasonableness behind his own impressions? That he can explain or find a reason for them can be of no importance, so long as he can "work from them with as much certainty as if they were embodied upon paper." For instinct leads and theory follows, as we see in the fact that the laws and rules of all arts are formulated upon the discoveries of each new true creator.

To return, however, to our impressions of nature; among the more gross effects which we all notice and accept are the lines made by the falling rain and the disappearance of the spokes of a rapidly turning wheel. But there are an infinite number of less obvious effects and changes of appearance associated with movement in nature of which certain artists instinctively make use, especially modern artists since the development of impressionistic realism-such as indistinctness, confusion, reduplication and even apparent deformation.

We shall agree as to the confusion and indistinctness due to movement in nature. And in art examples are not hard to find. Millet in his "Woodman" makes the hand that swings the chopper less distinct than the hand that holds the faggot. We shall agree, too, I think, about reduplication. Does not a cane in rapid vibration give a double image through being more distinct at either limit of its oscillation? Daumier in his "Mountebank" beating a drum draws the drum-sticks with double tips.

As regards deformation, there may be some disagreement, and yet it is a truth to nature that is instinctively employed for expression in art. Difficult as it may be to realize it in subtler instances, if we take the simple case of the appearance of a circle created by an object swung rapidly about a centre, we shall notice that, as it acquires motion, it not only becomes less distinct but is also elongated in the direction of its flight.

A very noticeable instance of deformation occurred one evening at the circus, where an acrobat was juggling with a number of sticks, which he made to turn rapidly over and over as he tossed them in the air. The sticks, though straight in themselves, appeared so curved that anyone who had not seen them at rest before the performance began would have denied that they could be straight. This is but an extreme instance of what often appears in the limbs of men and animals in motion. Another instance was that of a photograph of a racing motor-car. The photograpl of the motor-car had been taken with a shutter that was not rapid enough for such 
a subject, thereby approaching the condition of human sight. It showed the rim and spokes of the wheels distinct and exact where the tyres touched the ground, but blurred and pulled forward at the top where they were advancing more rapidly.*

The duty of the spokes, which are the legs of the machine, is to thrust forward the axle to which the car is attached, just as its foot and leg thrust forward the horse. We are so much inclined to watch the mass of the horse as it gallops that we think of it as swinging its legs to and fro past the indistinct landscape; we do not observe the hoof stationary upon the ground propelling the animal forwards. Yet this is actually what occurs, and such pauses in the motion affect our impressions, so that as a man or animal leaps, fights or dances, a tail, a sword, a piece of drapery, a foot, a hand will

* Some reader may perbaps exclaim "one part of a wheel can't advance more rapidly than another!" Rotate faster, no ; advance, yes.

The diagram shows the positions of two points on opposite sides of the wheel called $A^{1}$ and $B^{1}$, and the positions called $A^{2}$ and $B^{2}$ which they hold when the wheel has

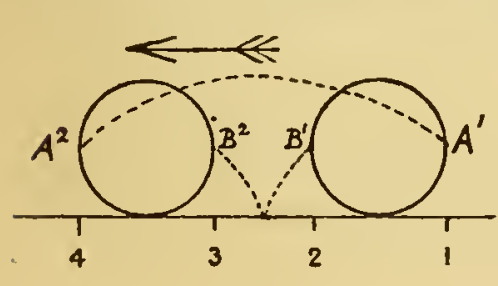

D sometimes seem to hover or lag behind, even making the limb appear too long.

The artist in his truth to his impression will be led insensibly to see and use such accurate "inaccuracies" upon which the exact effect depends. For such " inaccuracies" are but normal alterations of appearance due to movement, which correspond in principle to the fact that colour is modified by the colour that is placed against it, or that a white flagstaff, which looks light against a house, looks darker and thinner where it comes against the evening sky above it, and must be so painted to give the effect, although we know it to be actually of the same tone throughout its length. And so it is not only for the pattern of the picture that the leg which is too long in Rubens, the limb which is deformed in Degas, are right, but also in truth to the natural appearance for those who can see. Or to take another instance, are not trees at a distance certainly as green of leaf as those near by ? Yet who would argue that we ought to paint them so, denying the modification to blue due to intervening atmosphere? And yet the first distant trees painted blue must have shocked the early art patron.

An artist who is constantly watching and enjoying motion like Degas, to whom such changes are familiar, and who accepts them as part of natural 
appearances as simply as he does the difference of form in a muscle at rest or in action, will necessarily

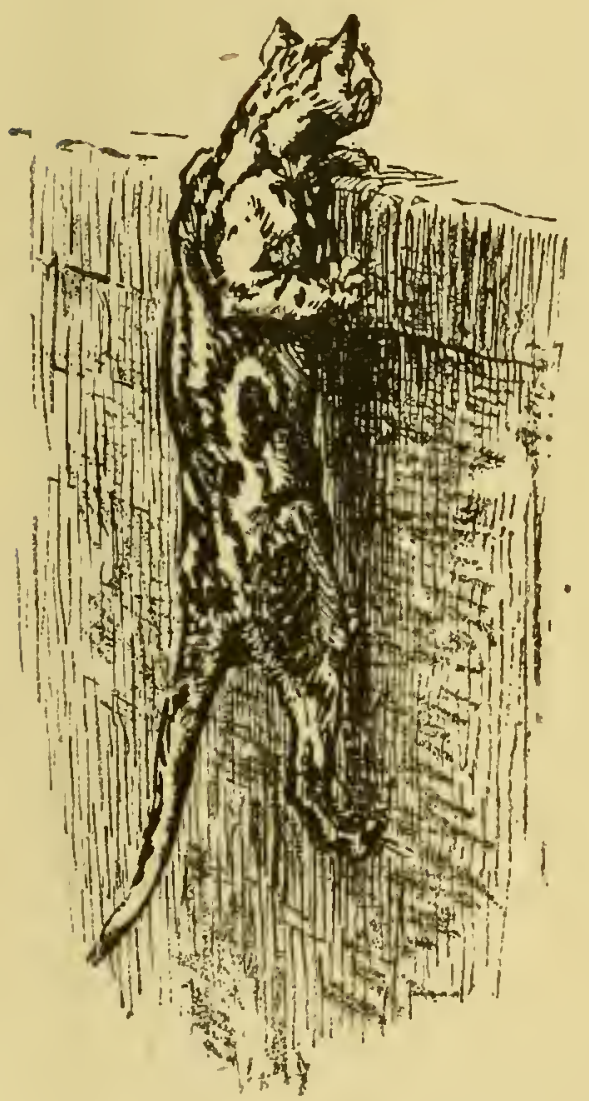
introduce them into his work, either so subtly as to pass unperceived by most people, or so frankly as to shock and distract some spectators. And however much he may use the posing model in order to acquire knowledge of form and construction, he will never substitute its shapes for those he had observed in motion. Sometimes one sees a figure which is meant to express movement drawn with all its muscles tense. The model, not the artist let us hope, no doubt thought he was showing the beauty of his limbs, and did not appreciate that to make the muscles on opposite sides pull against each other is to prevent all movement, and is only used in life when we want to hold a limb absolutely rigid.

To return to the question of loss of definition and apparent deformation of shape, it is interesting to notice how it can make for beauty. In a scientific cinematograph there was shown upon the screen a bullet in the act of striking an egg-shell dancing on a jet of water. To make it visible the speed of nature's movements was reduced so that the little black bullet crawled quietly across the screen to where the egg-shell lifted slowly up and down upon the weary column of water. It was very curious to see it deliberately push the egg-shell over and by so doing disturb the water-jet, which had to make two or three laboured efforts to recover itself. But from our point of view the interesting effect was the appearance of the drops of water. They were not the gay sparkling jewels we all admire. They were repulsive protoplasmic viscous-looking things, slowly changing from one ugly shape to another as they sank through the air. Is not the visual world then partly dependent for its beauty on its speed? Are not the drops of water rather like discords in music, pleasant to look upon, as the others are to hear, when passing at their proper pace?

Since art is art and not nature, is there not a certain 
measure to be observed in what is represented ? There are many optical effects which are not satisfactory when presented persistently, as they are in a work of art. The head of a dog as it shakes itself on coming out of the water leaves a confused blur upon the eye that is too transient in nature to be satisfactory in a picture, and yet it is not very different from the distorted and evervarying images of objects reflected in undulating water, which are quite acceptable when represented in a picture. Is it upon the effect being sufficiently persistent that the question turns-that the disappearance of the spokes of a wheel from taking place about a centre has, like the reflections in water, a certain constant character which makes the representation of a wheel without spokes quite satisfactory?

It is interesting to notice in connexion with the means of expression the difference of principle in the composition of pictures of movement and pictures of repose. In pictures expressive of repose the dominant principle of composition is a structure of verticals and horizontals, in a picture expressive of movement the composition is diagonal.

To take a few clear instances from pictures in the National and Tate Galleries. Horizontal and vertical are the principle of Turner's "Chichester Canal," varied with a few gentle curves, of De Hooch's "Interior," of Crome's "Mousehold Heath" which is divided into two almost equal spaces of moorland and sky by a straight horizontal line, relieved by the cart tracks and a slight movement of the clouds. For contrast look at these three turbulent pieces-Turner's "Shipwreck," Rubens' "Rape of the Sabines" and Tintoret's "Milky Way."

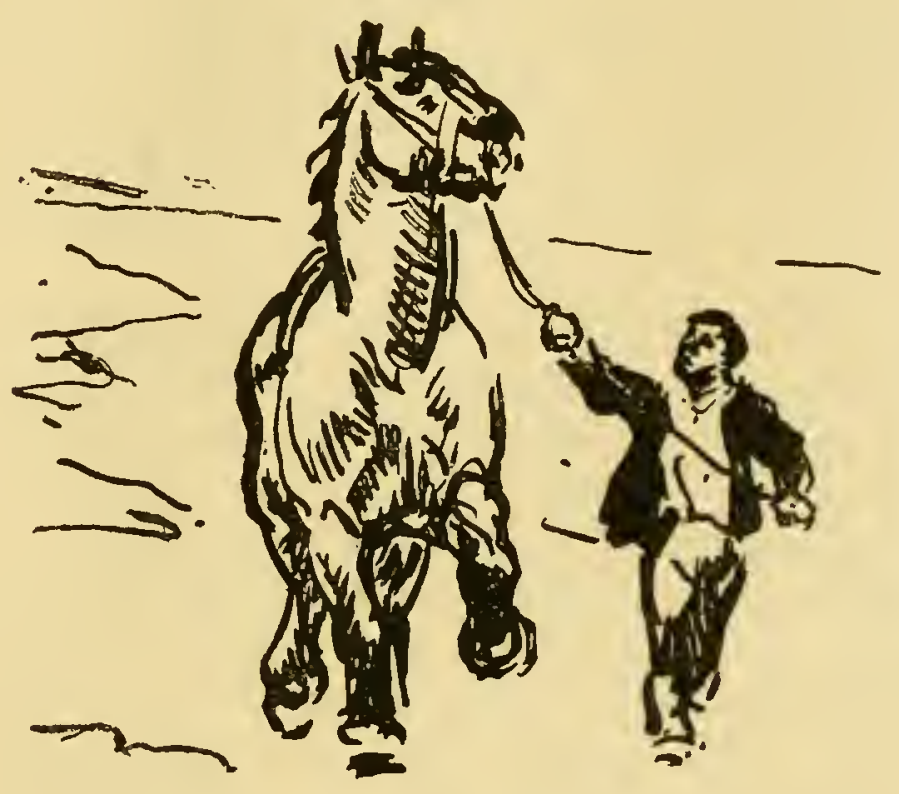




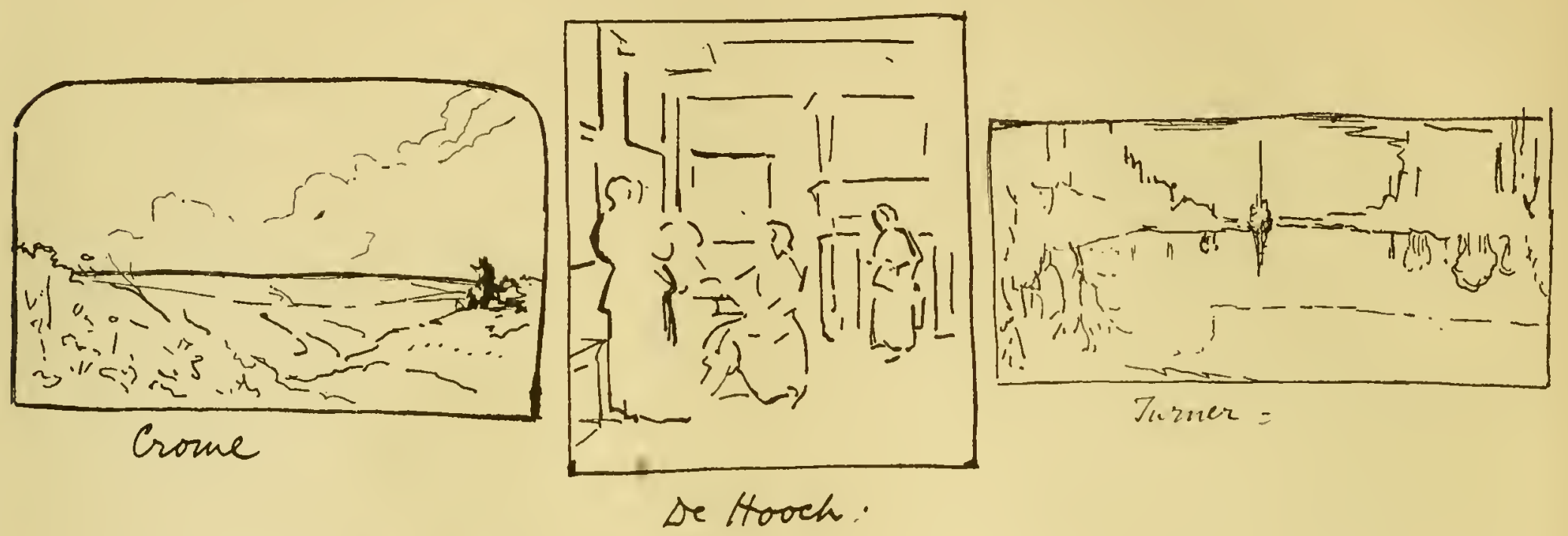

Rough diagrams are given of these six pictures for those who cannot refer to the originals. The light and shade is left out and the emphatic parts of the pattern are translated into line.

They do not claim to be accurate, being only rapid sketches from small reproductions, yet they make, I think, the characteristic difference of the two groups sufficiently evident.

The reader will remember that it was suggested that he should look at certain pictures upside down in order to observe the pattern for itself. Some of these dia- grams-he will easily detect which-are reproduced upside down the better to illustrate the principle of effect inherent in mere pattern.

Such differences are fundamental and are true to nature, being based upon what we see and experience every day. To test the visible repose of vertical and horizontal in nature tilt the picture frames and notice the restless effect that is immediately produced. You can't stand at an angle, nor can you push or pull as long as you remain upright. To push a thing you must lean towards it, else the thrust of your arms will push you 
over; and when you run you must incline your body forwards, or your legs will outrun your body and you will fall upon your back.

The horse leans forward into his collar, and back into his breeching; the driver leans against the cart to help it up the hill. In principle, walking, running, pushing are partly falling, and, as such, are inclined between the vertical and horizontal, the habitual positions of repose; and the artist, following nature, instinctively uses in pictures of motion patterns that are neither upright nor prone.

If in discussing movement I have confined myself practically to discussing it from the point of view of line patterns it is because rhythm, which is the essence of all movement, implies direction, and of direction the simplest expression is line.

Spacing, tone, colour, handling and other qualities have, of course, their place in heightening the effect of movement. There must be a sympathy between them and the rhythmic pattern of the picture. In the Tintoret, the Rubens, the "Shipwreck," there are sharp contrasts of tone and colour which would be out of character in the three quiet pictures. Is there not in this a consistency true to nature?

When we watch a scene of rapid movement or vigorous action only the stronger variations of tone and
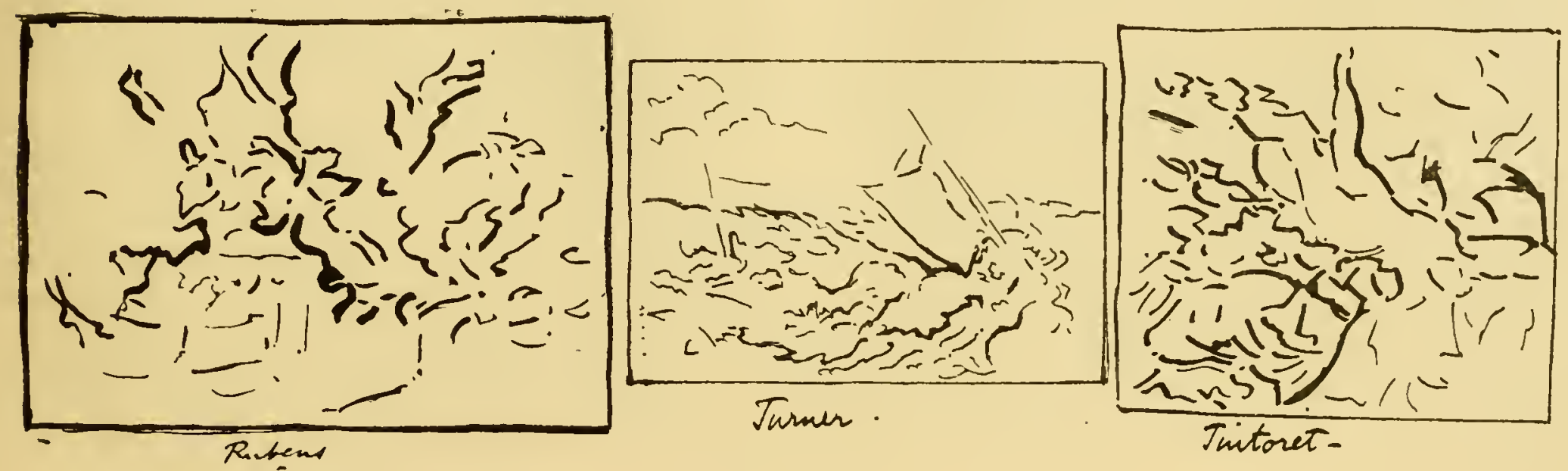
colour are to be observed by the eye. Is, then, the expression of movement a blunter and a coarser art ? Does true refinement occur only in quiet things? Is not the answer yes and no? For if refinements of form and spacing and delicate gradations of colour and texture are best to be enjoyed through the contemplation of things at rest under an even lighting, there are other refinements of beauty which are only born of movement.

An artist must decide for himself what rhythmic patterns will best express his impressions of particular movements, and how far he shall make use of such phenomena as we have been discussing. That is, he should let his eye decide for him. It will select by recollection what it was that interested him, and what, therefore, he will need to master for his work. Accordingly, he may prefer only to observe figures under movement and never to make studies from the model, or he may decide to study anatomy in order to acquire a knowledge of the bones and underlying structures, or, again, rely for such knowledge on observation of the surface alone. Instantaneous photography, which is the anatomy of movement, bearing much the same relation to it that the skull does to the face we see, might be useful to him, but it would be, I should say, a treacherous ally. If we look at the studies and sketches of those who could seize nature on the wing and render her effects, we shall find that they mostly worked through unflagging observation helped out with quick notes, shorthand records often legible to themselves alone. They amplified such slight notes through knowledge of the form and the movements of the figure, either taking such knowledge from their general stock or specially acquiring it for a particular subject. For this purpose some of them make minute and elaborate studies from the model, like Degas; others, like Daumier, depend apparently upon repeated observation and memory alone.

Observation seems to be the keynote, the passive observation which does not start out, having settled in advance what it wants to see, but is ready to see what nature will disclose. Nature, as a great artist said, will give to each man according to his powers, if he will but sit humbly at her feet.

Such an attitude is surely the right one in all arts, and the fun of it is that the artist whose preference is against movement will be led, quite rightly, to turn his back upon it and upon all that we have been discussing, and perhaps go off with the gentle Chardin to share the charm of contemplation almost Oriental in its quiescence.

As movement, however, can only be perceived through recollection of its phases, it is not possible, as has been 
already pointed out, to draw it from a stationary thing. It can never be copied from a posing model, for there it does not occur. A good illustration of how not to do it is given by Verestchagin in his recollections of Meissonier. He tells us that when painting a horseman riding against a strong wind Meissonier had a little model with the costume and accoutrements of horse and rider made to scale in their proper materials, that he might have before him the correct details, and the rider's cloak was stiffened with gum so that it stood out in the position of a cloak blown by the wind! I think we may fairly ask would
Meissonier, if he could, have stiffened the trees in the landscape so that they would remain in the position of trees blown by the wind?

No ripple on the grass or water, no quiver of a bough or leaf! Think how you would enjoy your walk in such a scene! Think what a landscape picture you would paint from it ! Surely Corot is right in his attitude when he says, "Although when I was young it annoyed me that the clouds would not keep still, now I am glad they will not, for therein lies their beauty "!

Paris, I92I.
L. D. L.

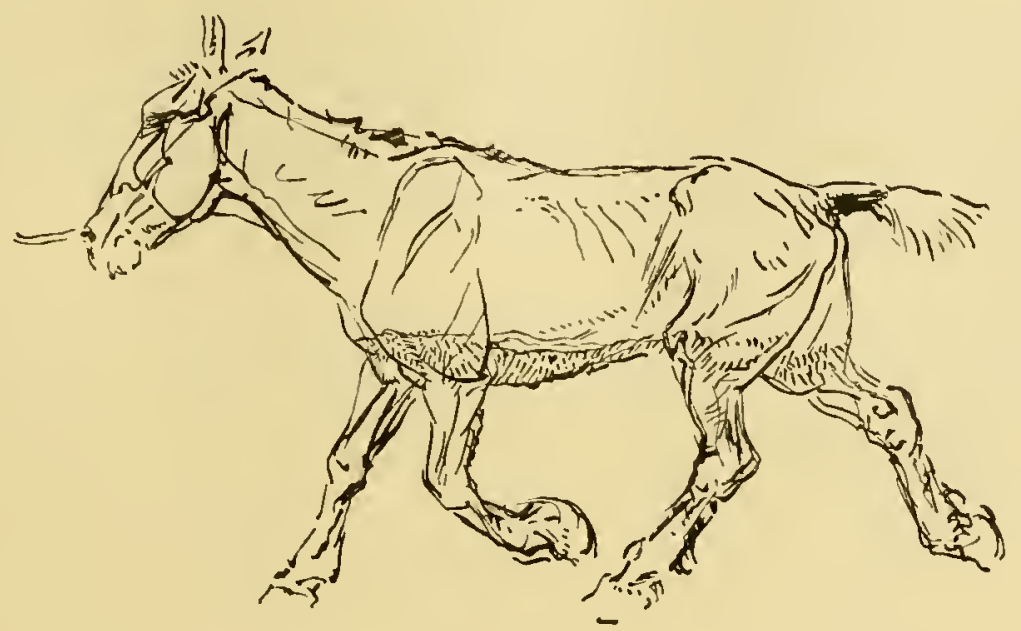

The suid. 


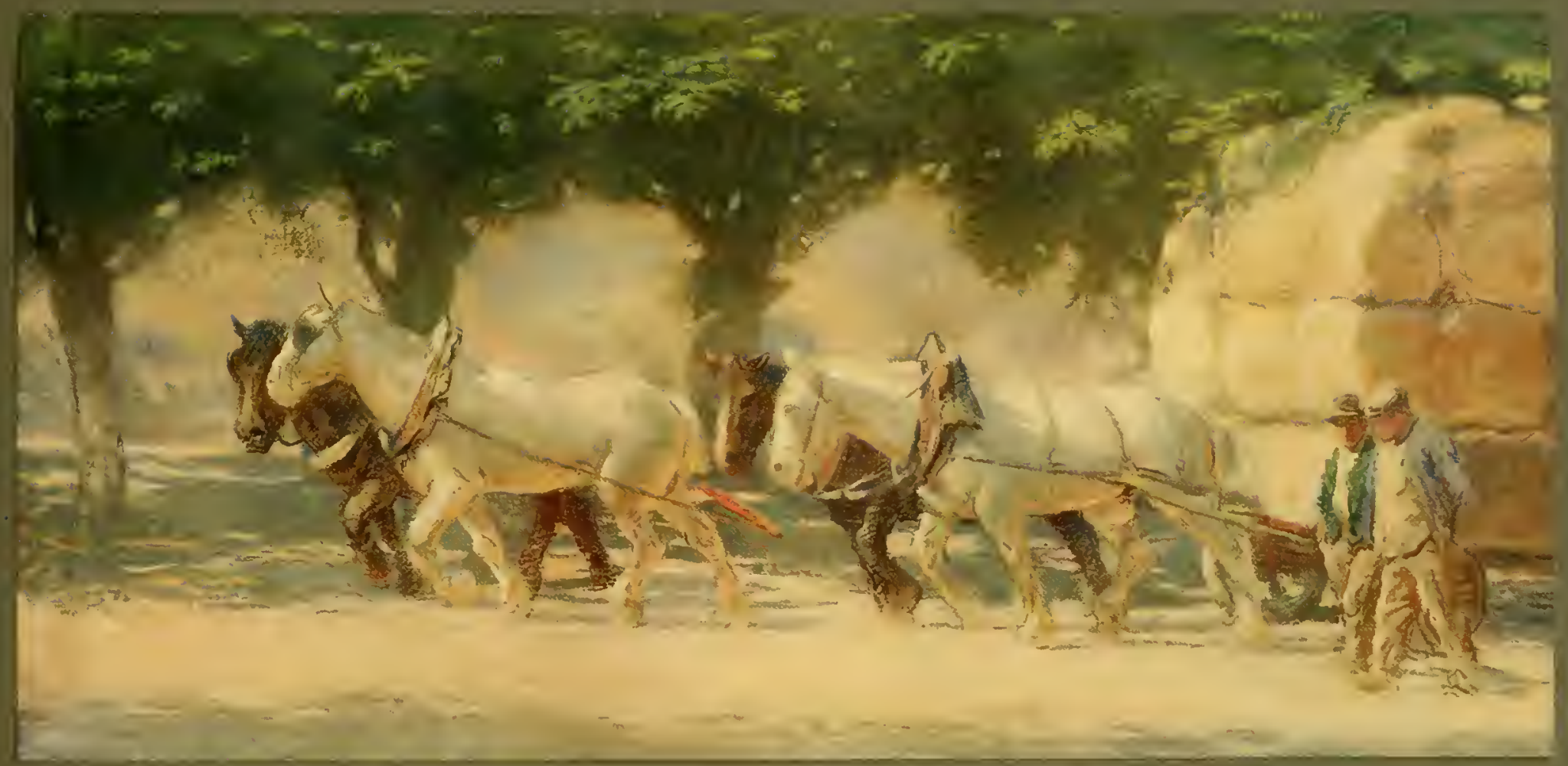

2. UP THE BOULEVARD. $(47 \times 23 \$)$ 


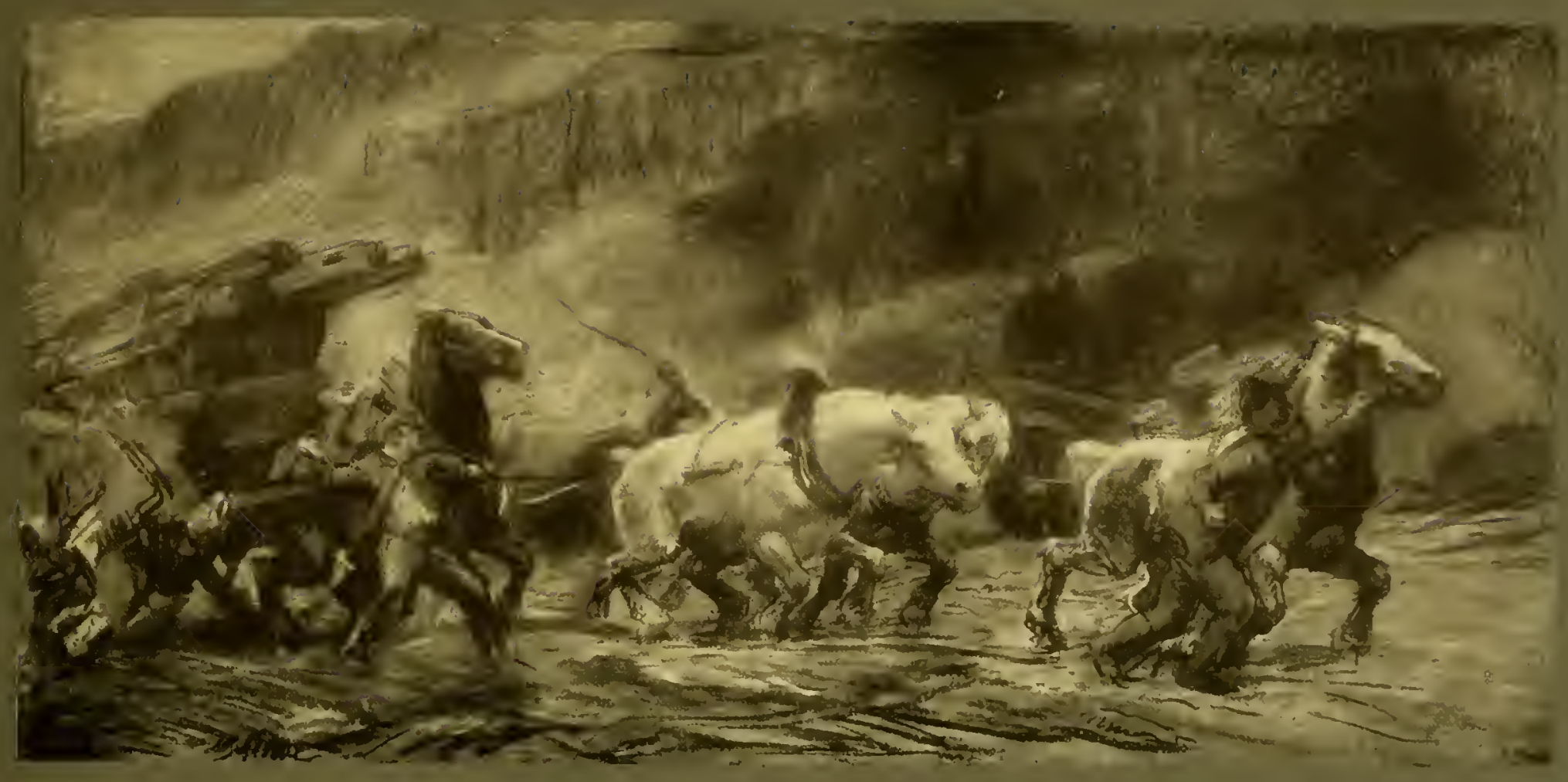

3. COUP DE COLLIER. $(49 \times 29)$ 


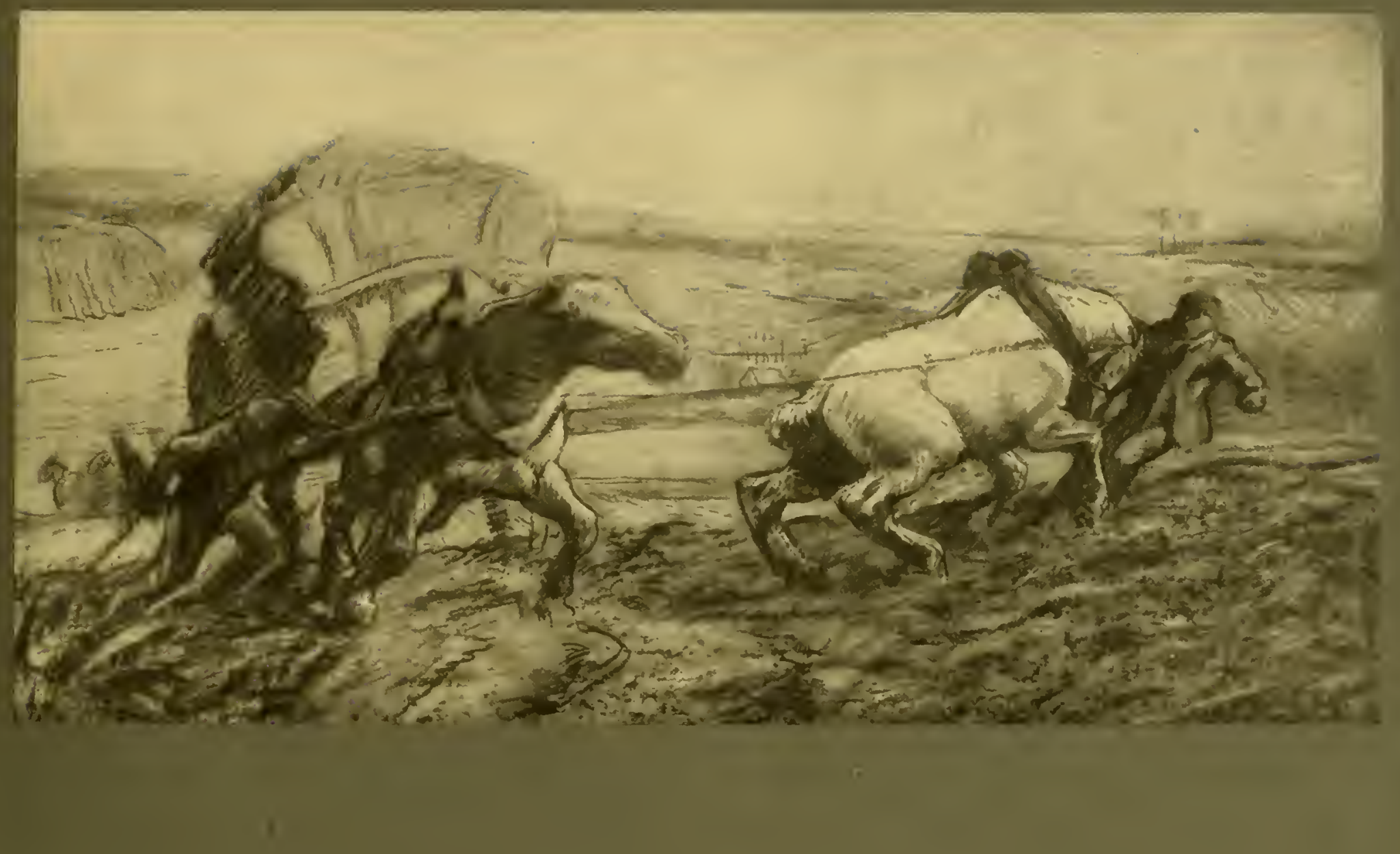

4. TOURNANT LE TOMBEREAU. $(52 \times 28)$ 


$$
\ln x \times 3 x
$$




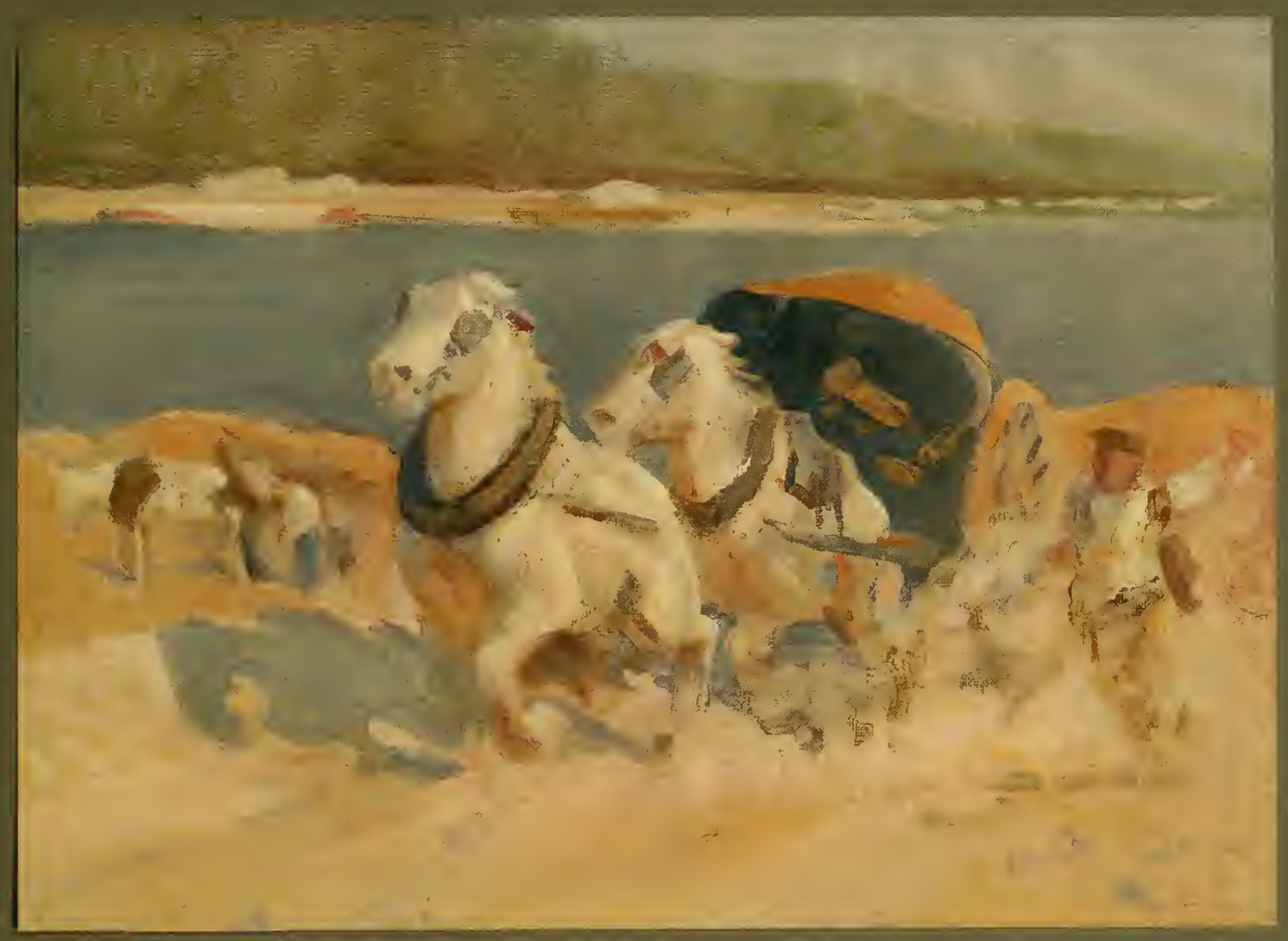

6. CHARGING THE SLOPE. $\left(18 \times x_{3}\right)$ 


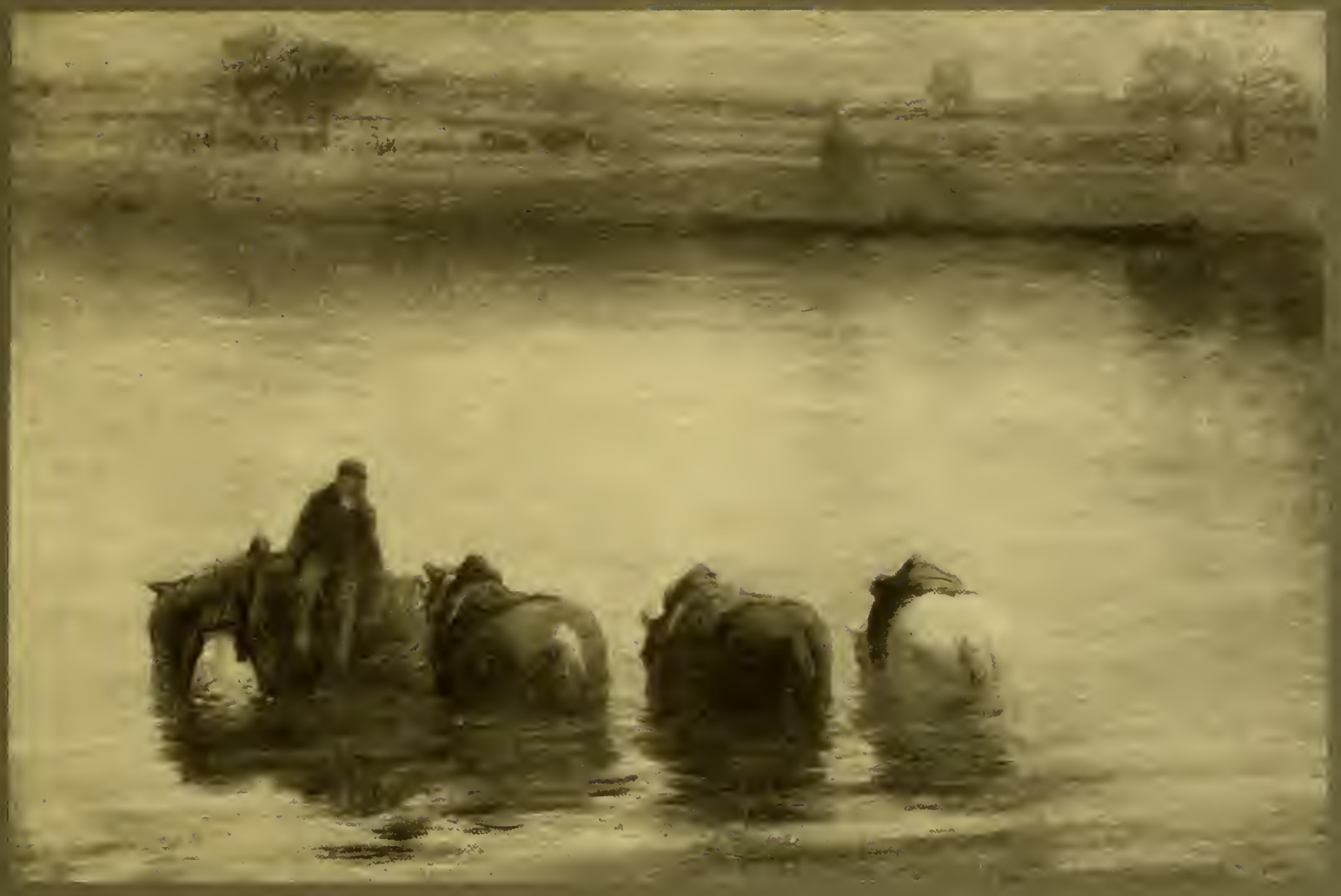

7. AT WATER: UP THE SEINE. $(36 \times 24\}$ 


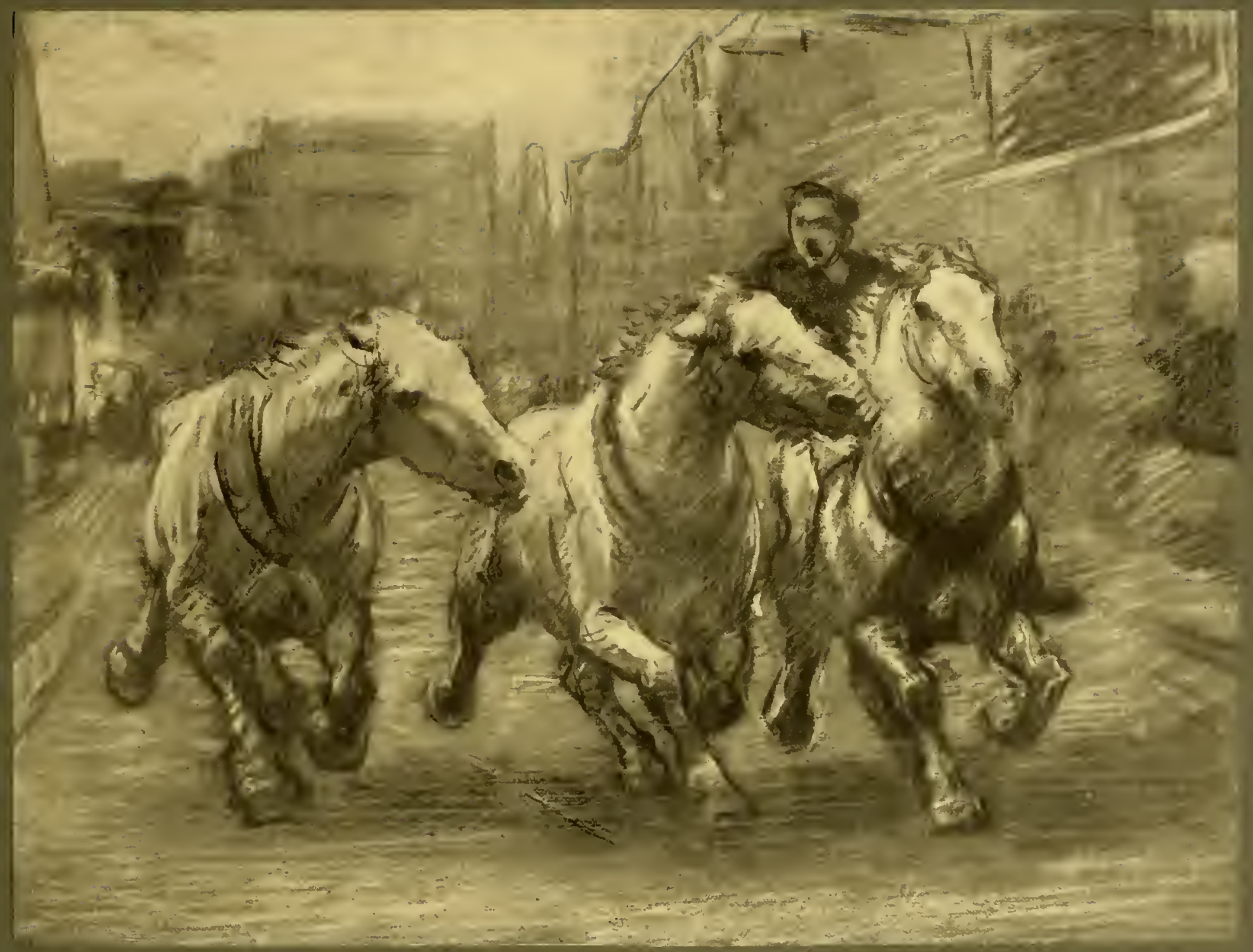

8. TROTTING: PARIS 'BUS TEAM. ( $18 t \times 13 \downarrow)$ 


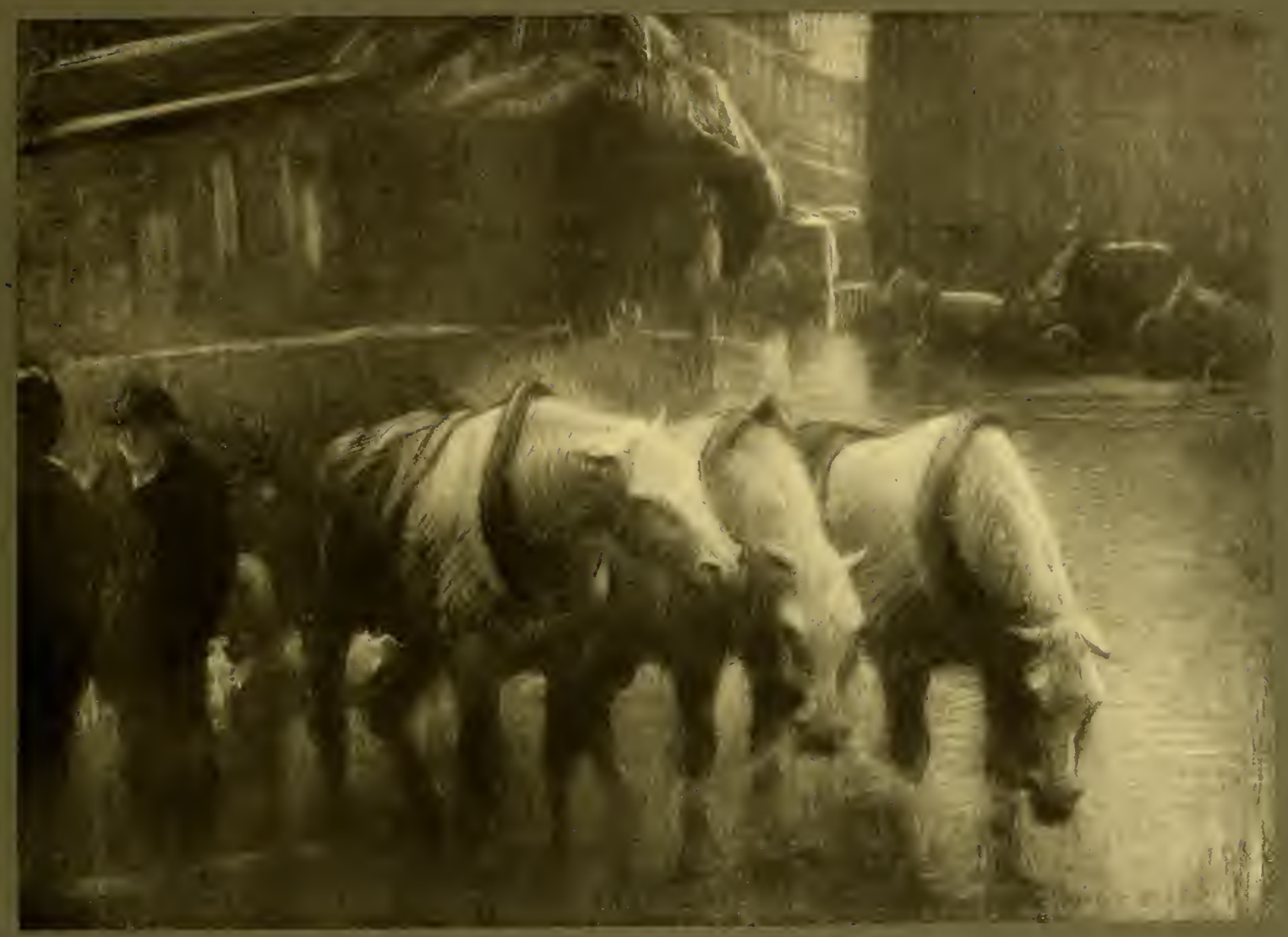

9. BETWEEN THE STAGES: PARIS. $\left(29 \times 22 \frac{1}{2}\right)$ 


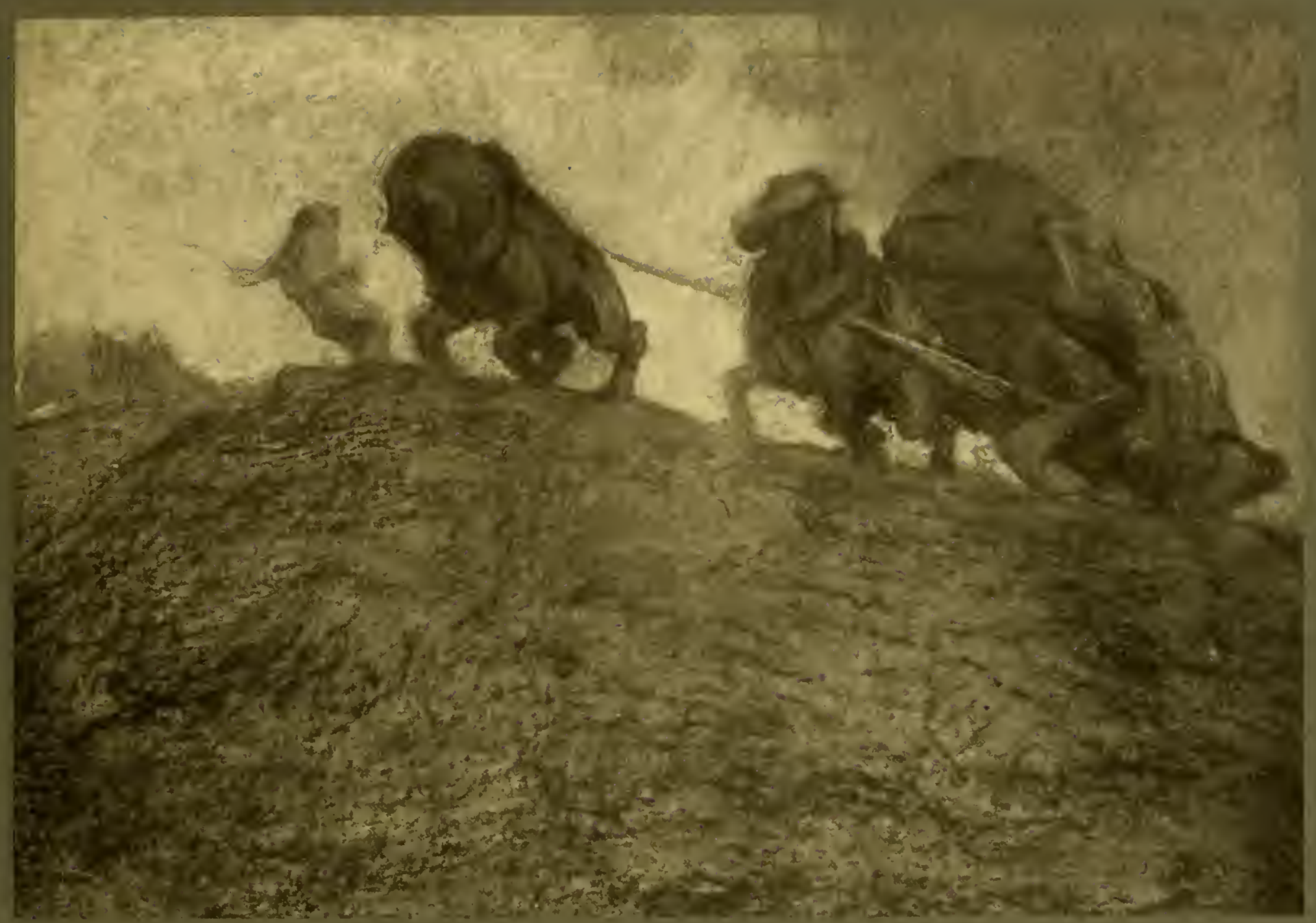

10. ON THE TOP OF THE BANK. $(28 \times 20)$ 


\section{?}

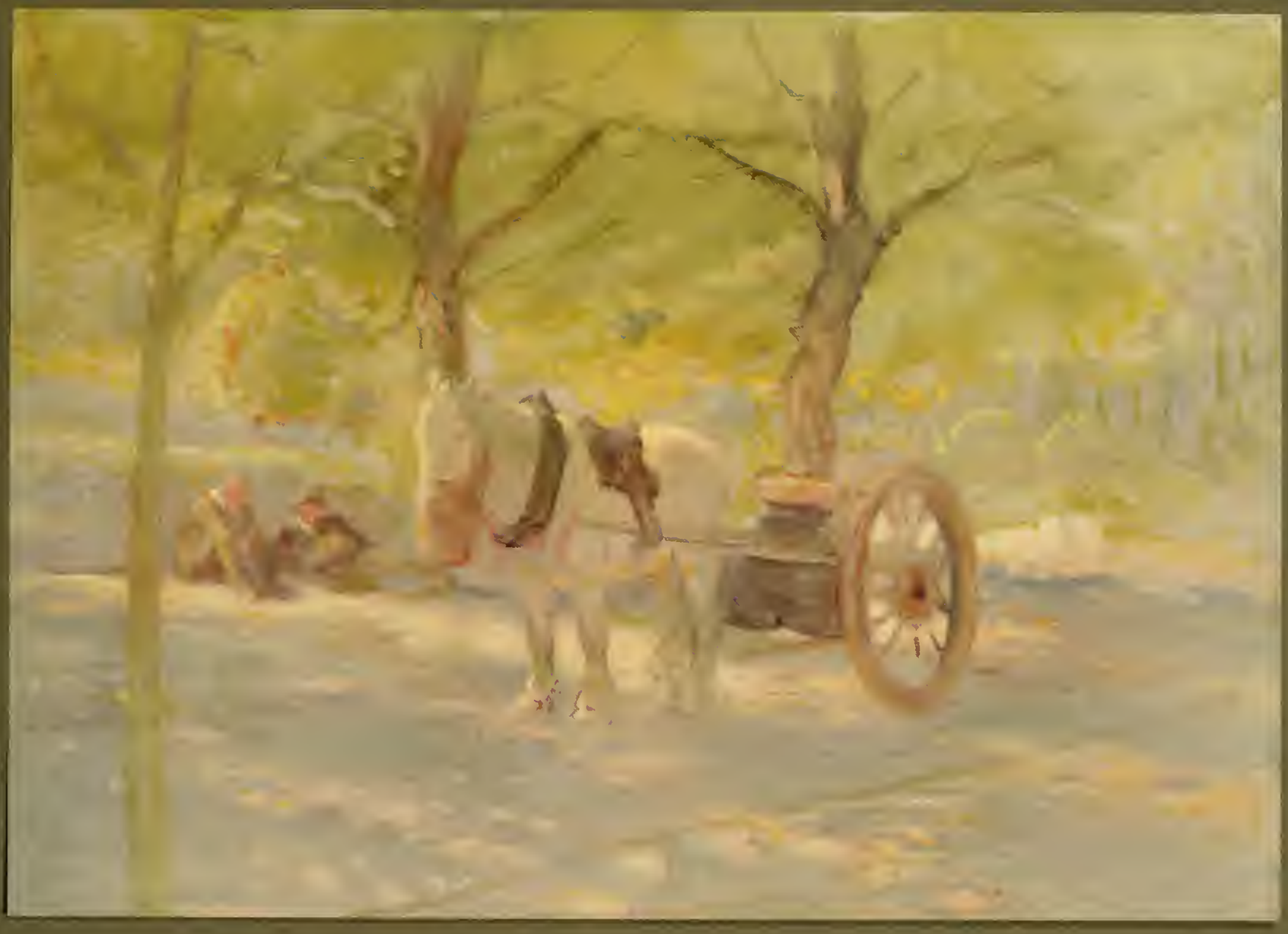

11. UNDER THE TREES. $(18 \times 13)$ 


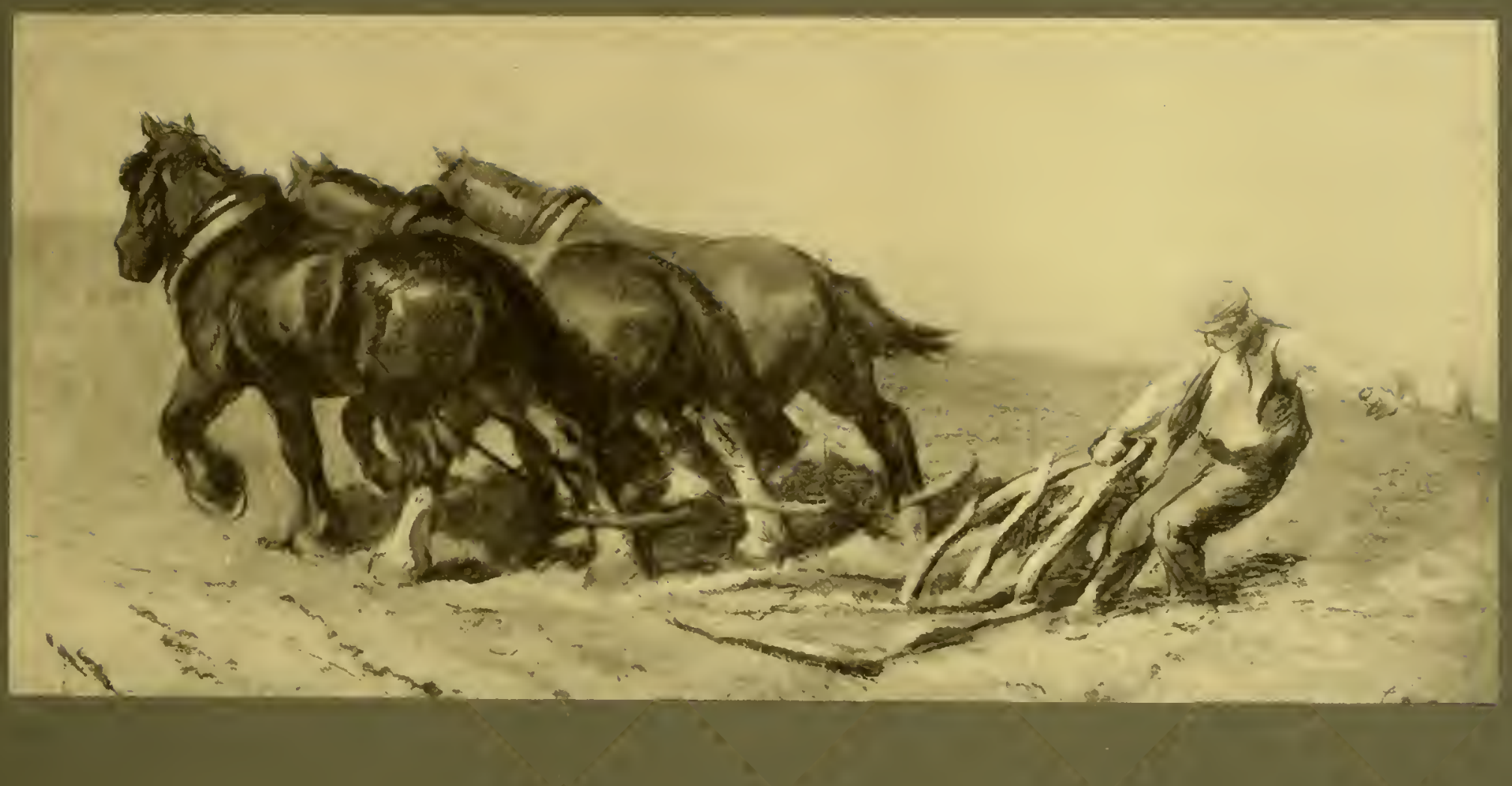

12. HARROWING. $(48 \times 23)$ 


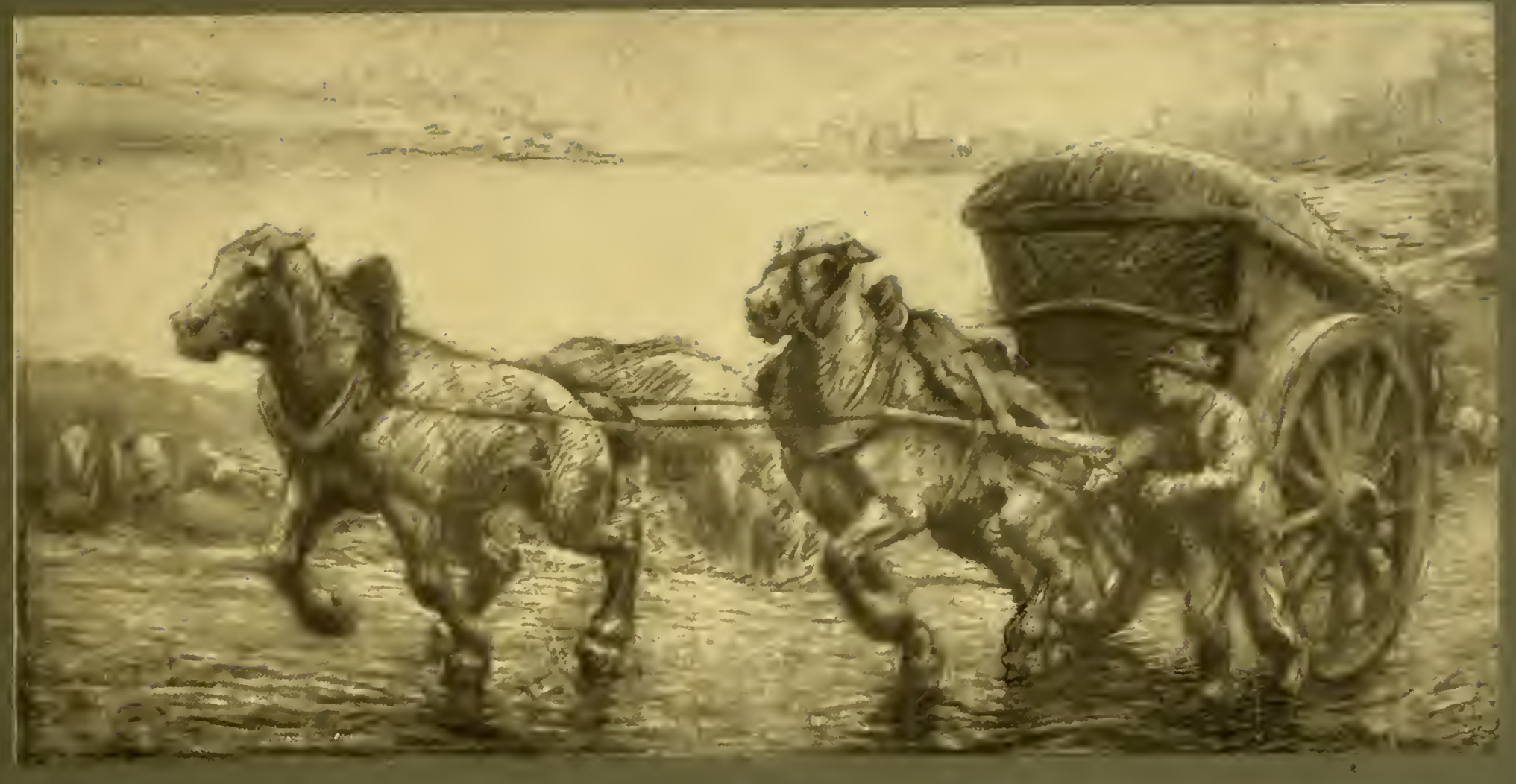

13. UP THE "RAMPE" $(40 \times 2 I)$ 


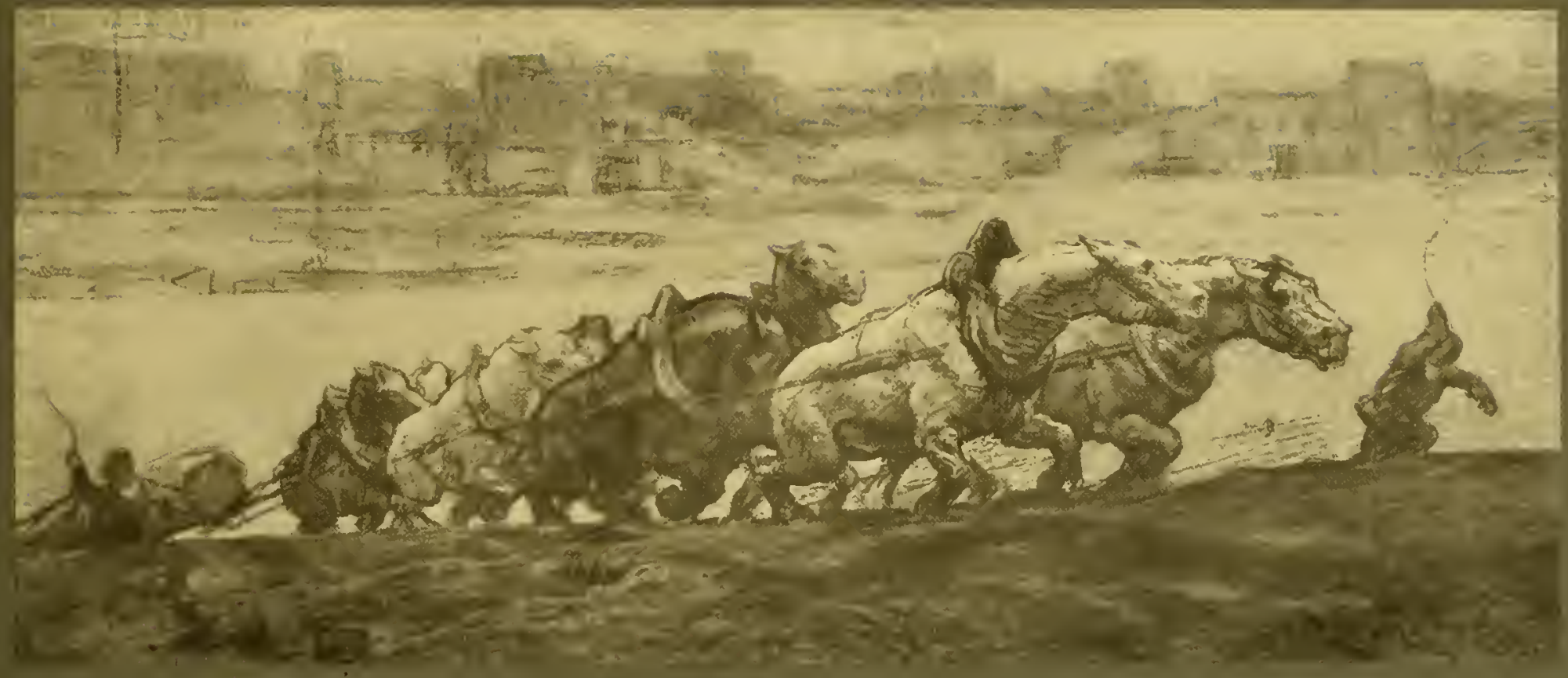

14. TIMBER-HAULING ON THE SEINE. $(72 \times 36)$ 



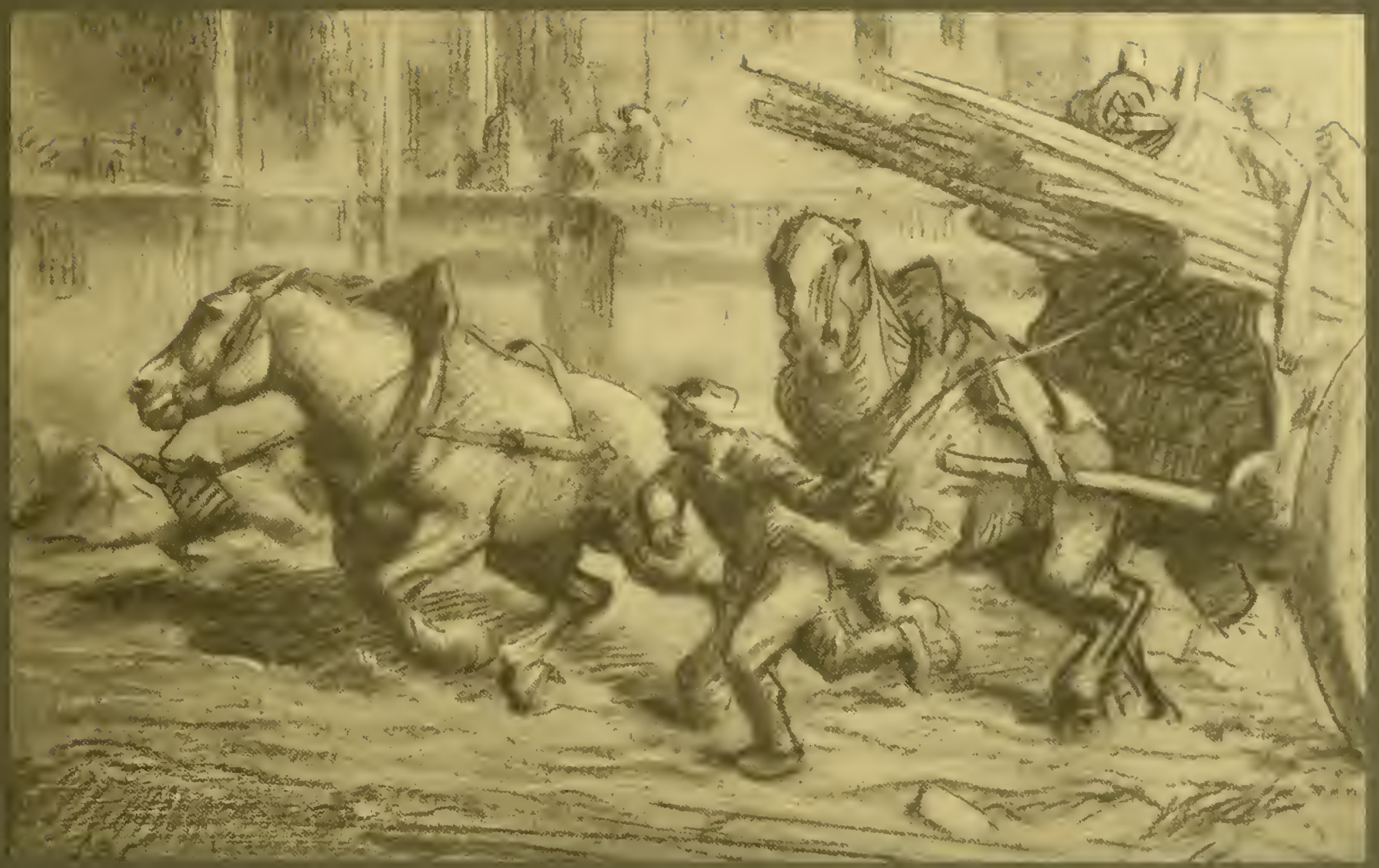

15. SPRINGING 'EM. $(32 \times 23)$ 


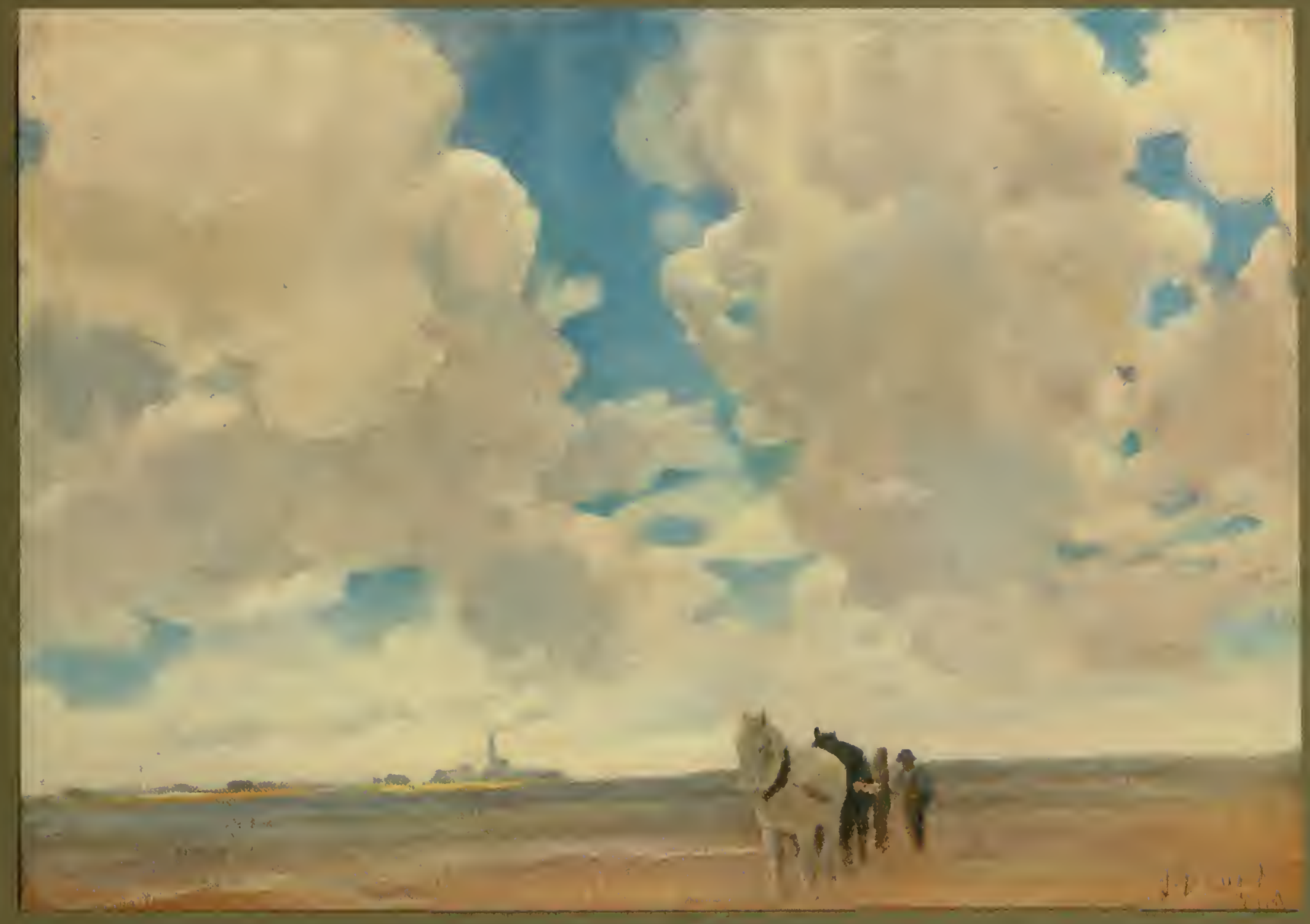

16. A SUMMER SKY. $(\mathrm{I} 8 \times \mathrm{I} 3)$ 


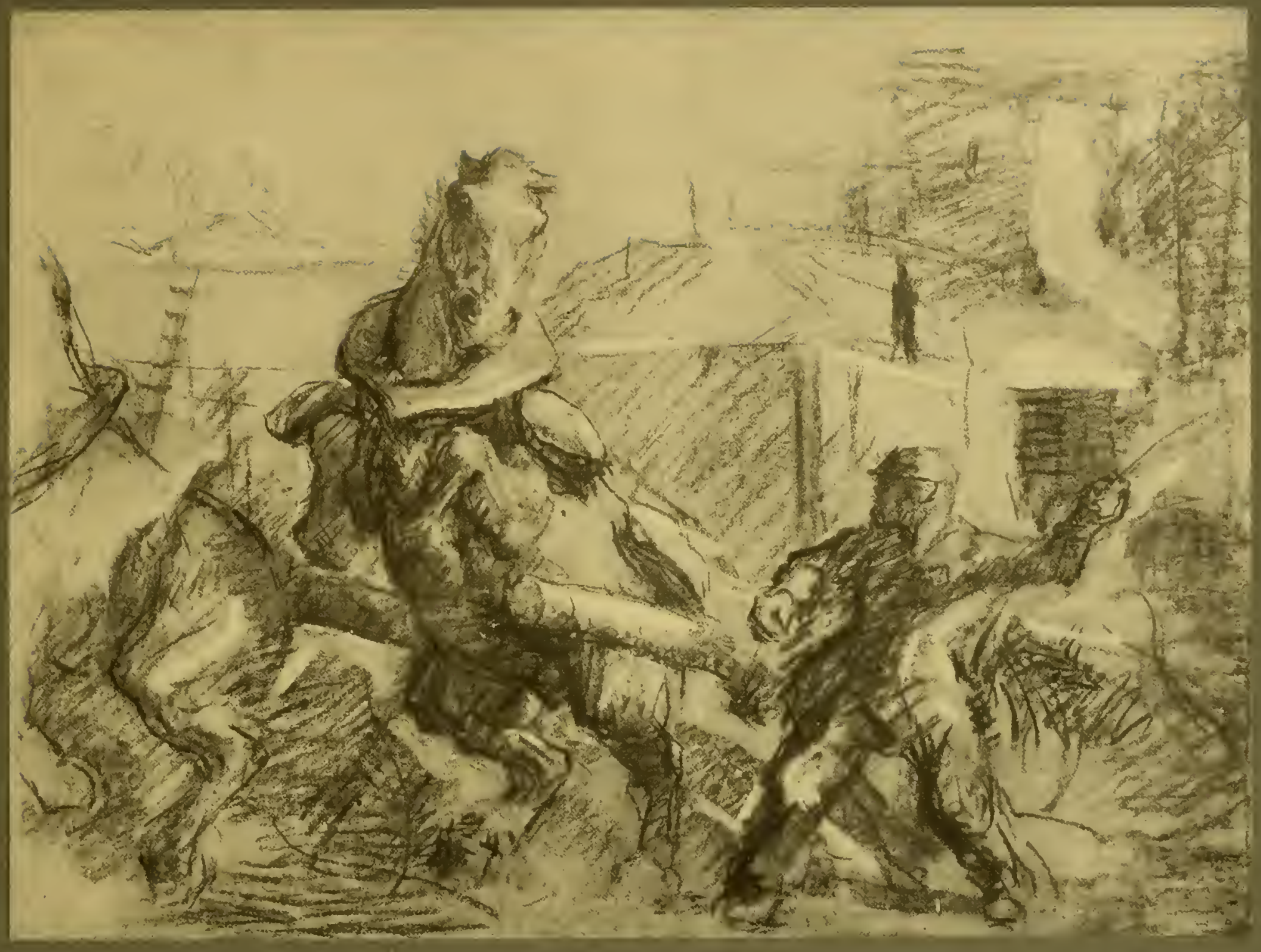

17. THE SHIRKER. (30 $\times 18)$ 


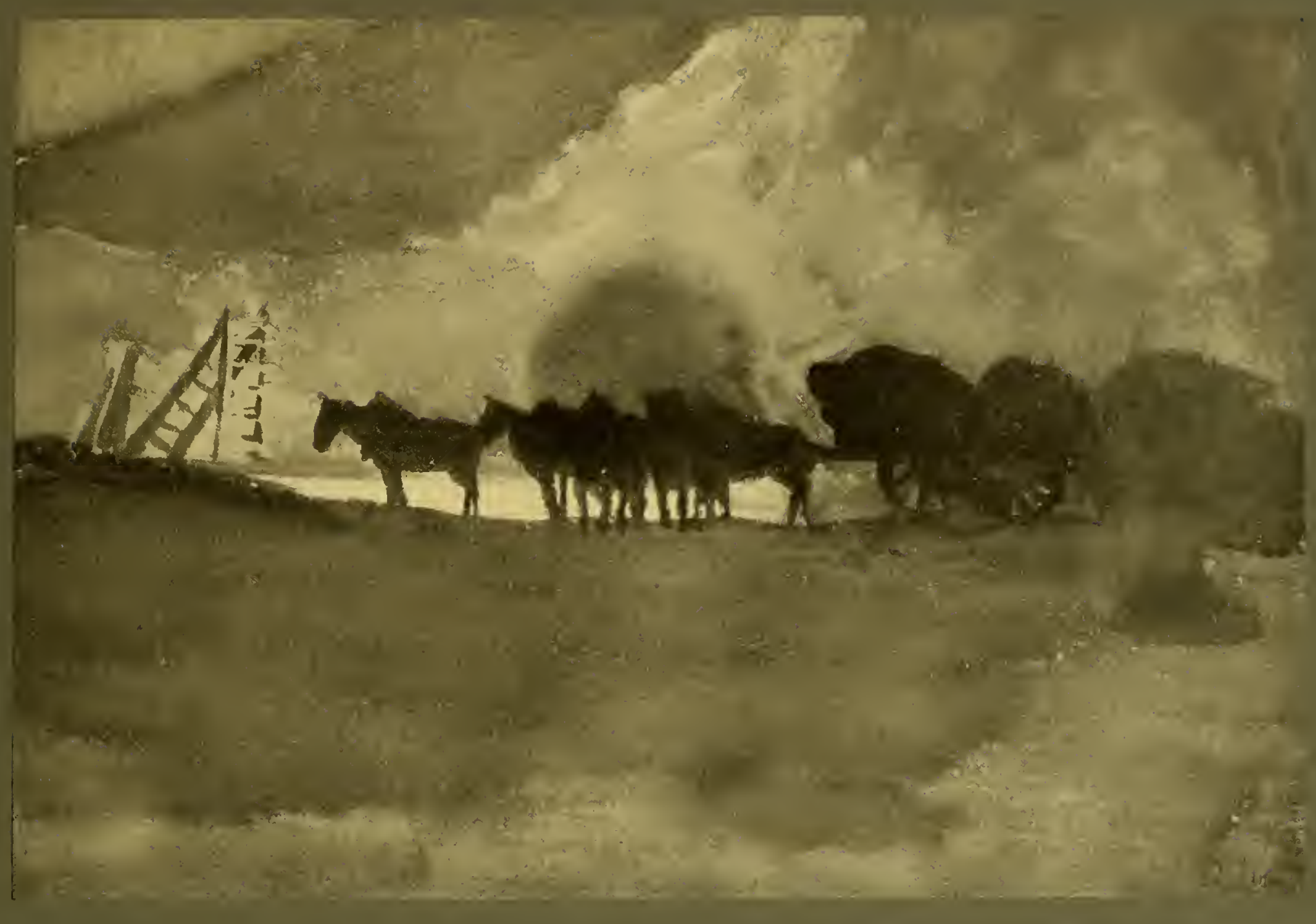

18. NIGHT WORK. $($ IO $\times 7)$ 
군 


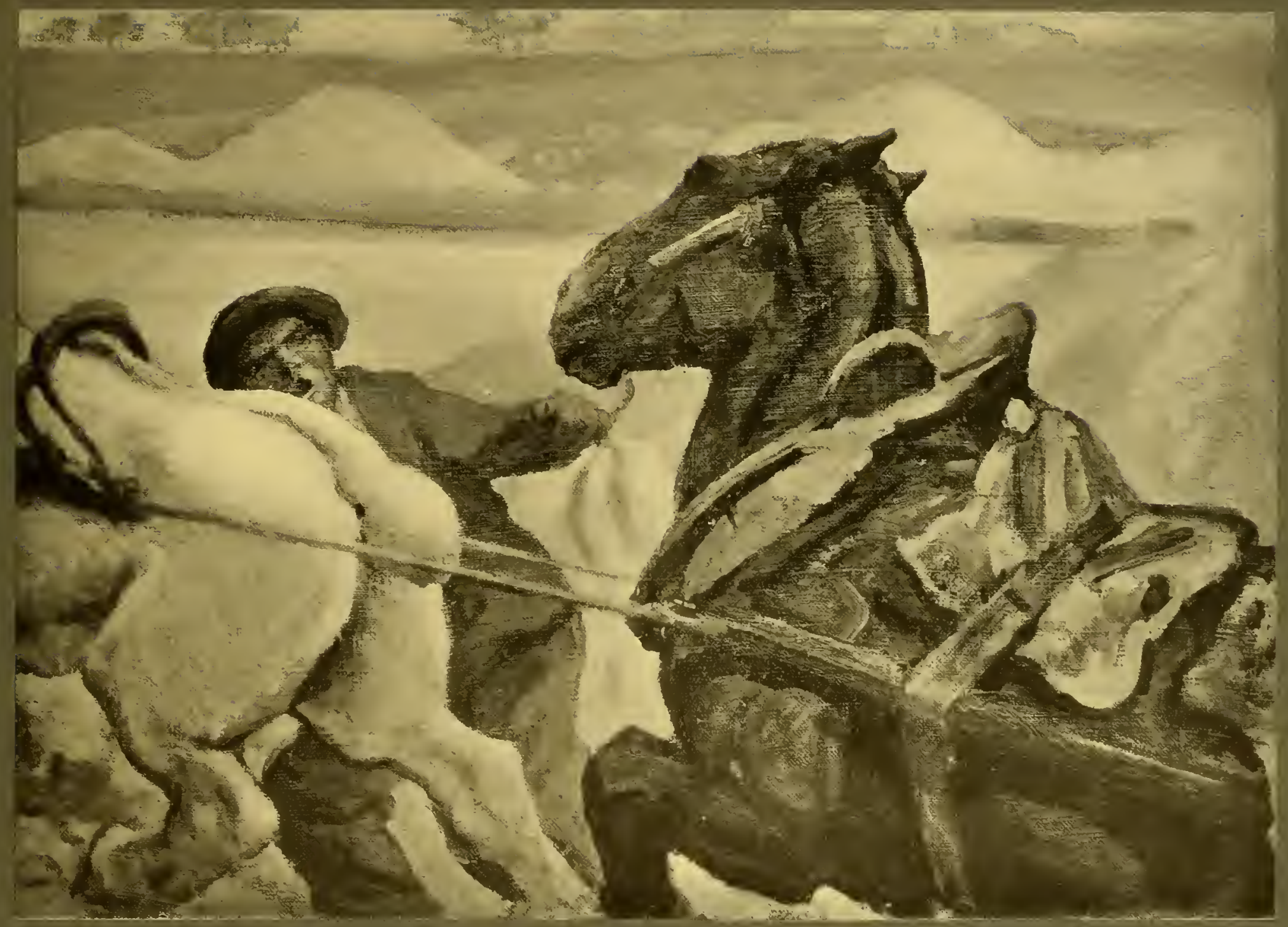

19. THE BLACK HORSE. (Oil Painting, $18 \times 13$ ) 



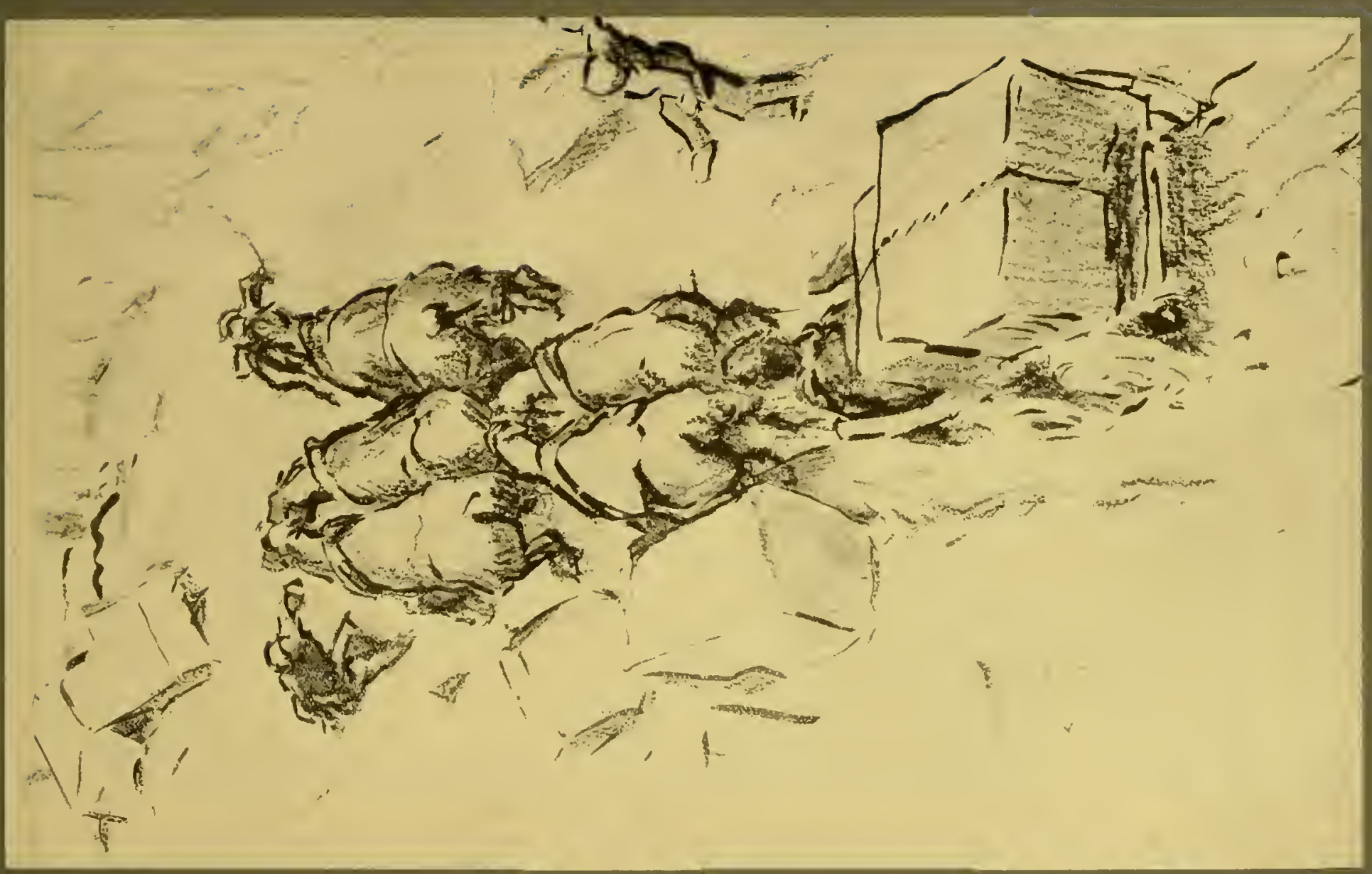




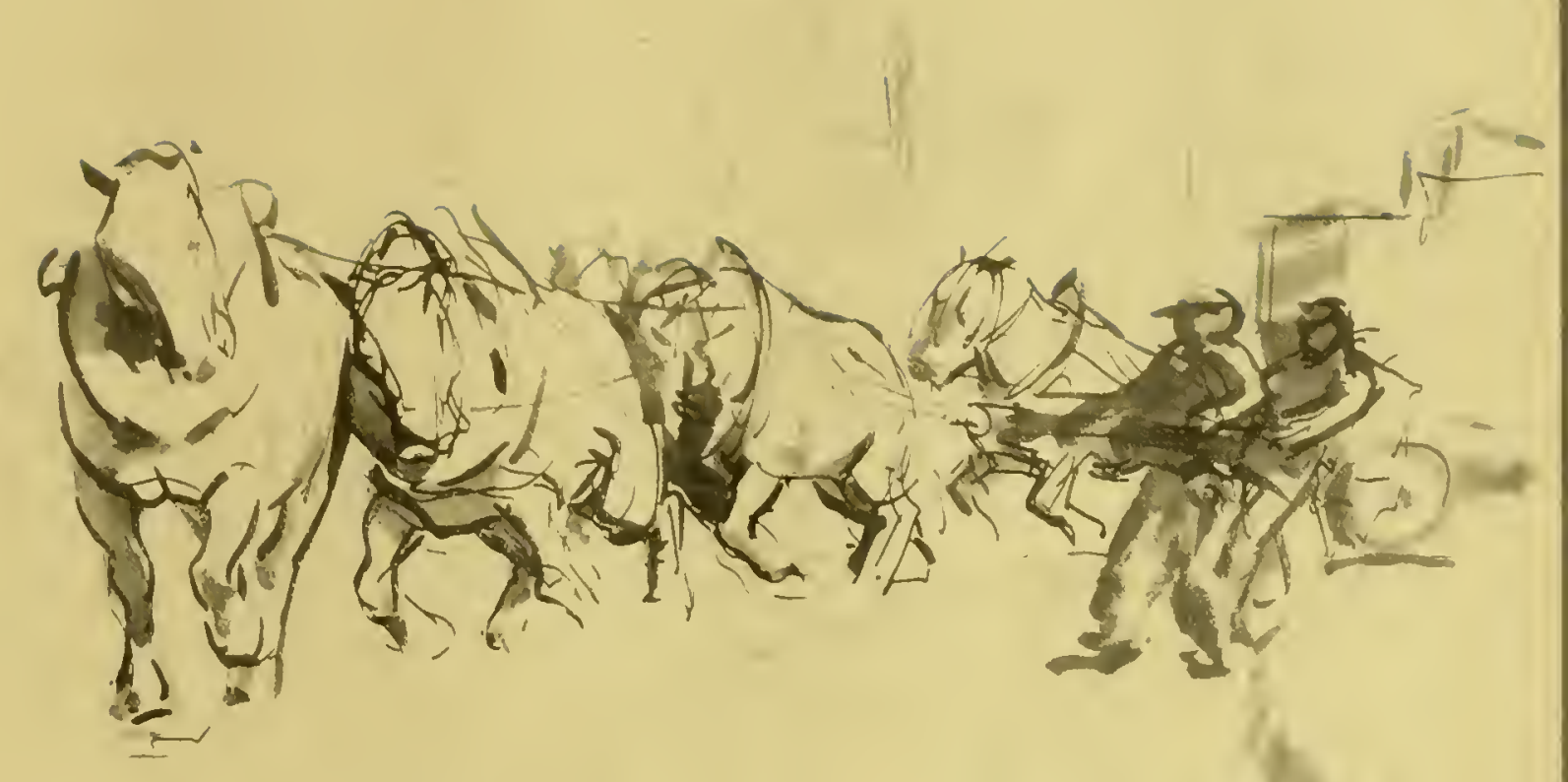

21. TURNING THE CORNER: FRENCH STONE-CART. $\left(I C \frac{1}{2} \times 7 \frac{1}{2}\right)$ 


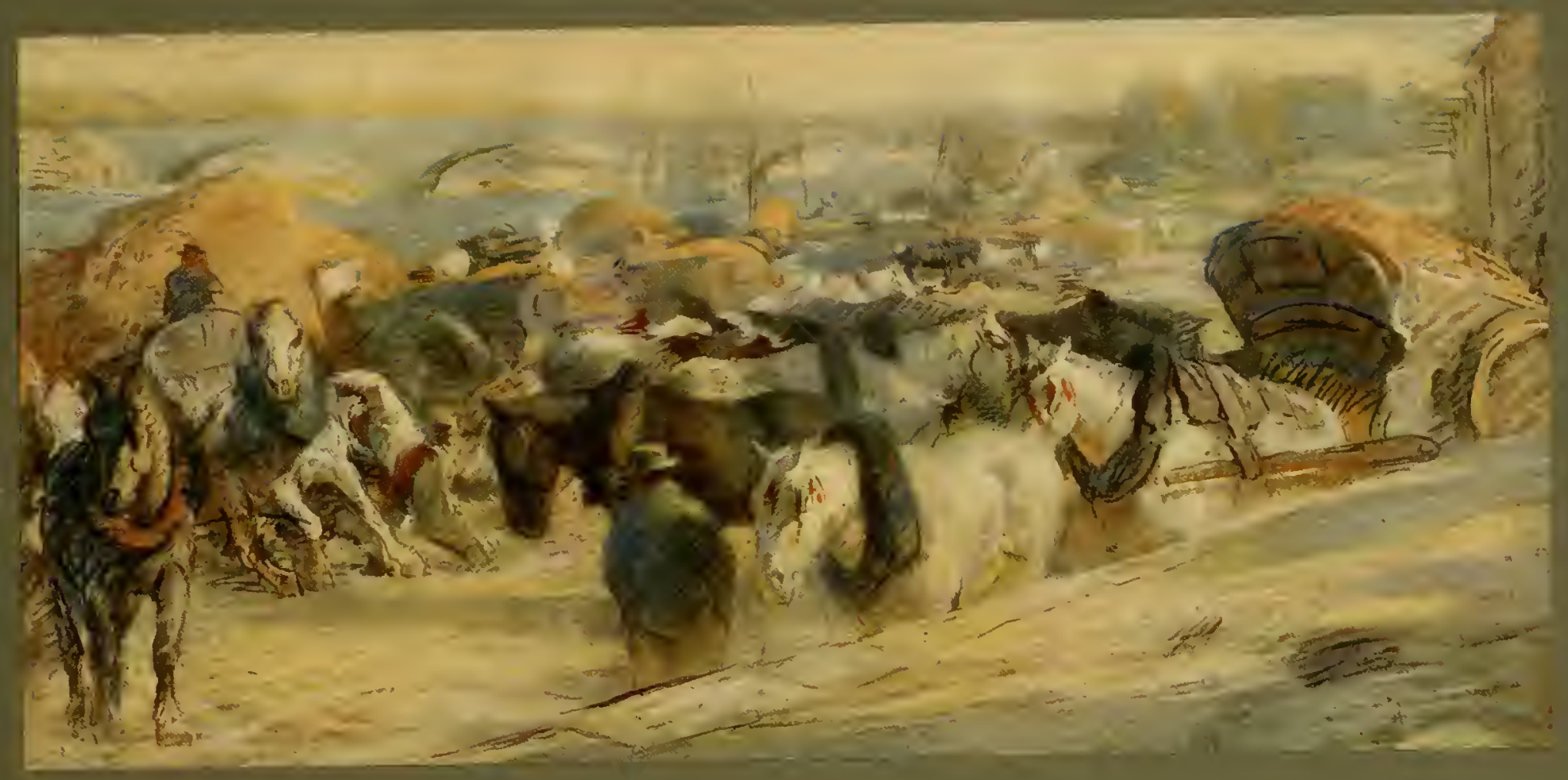

22. THE SUNNY QUAY. $\left(33 \frac{3}{8} \times 16 \frac{1}{8}\right)$ 


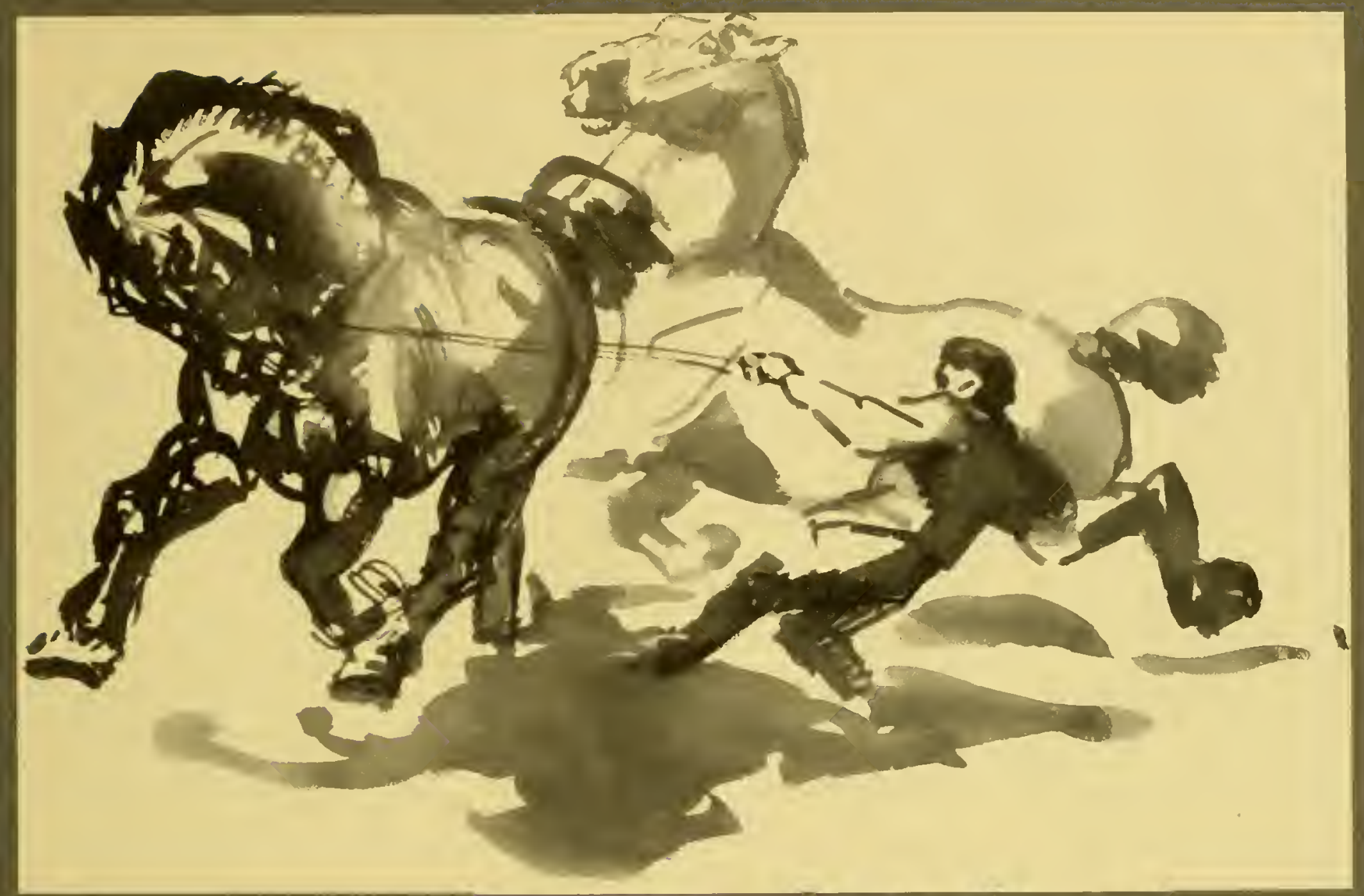

23. LED HORSES. $\left(9 \frac{1}{2} \times 7 \frac{1}{2}\right)$ 


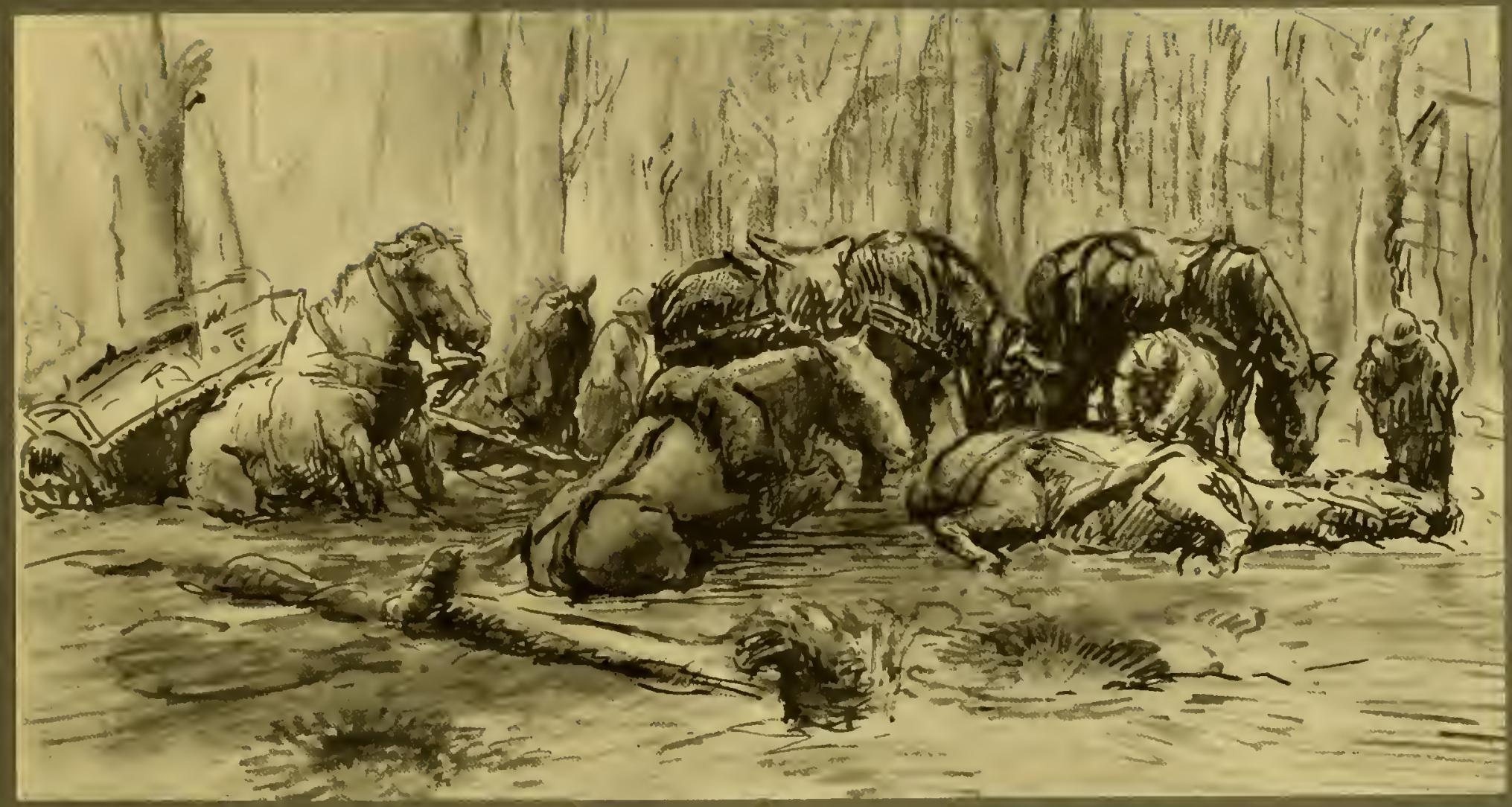

24. DEAD BEAT: FRENCH ARTILLERY, THE SOMME, 1916. $(23 \times 16 \$)$ 


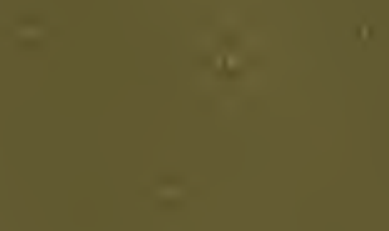




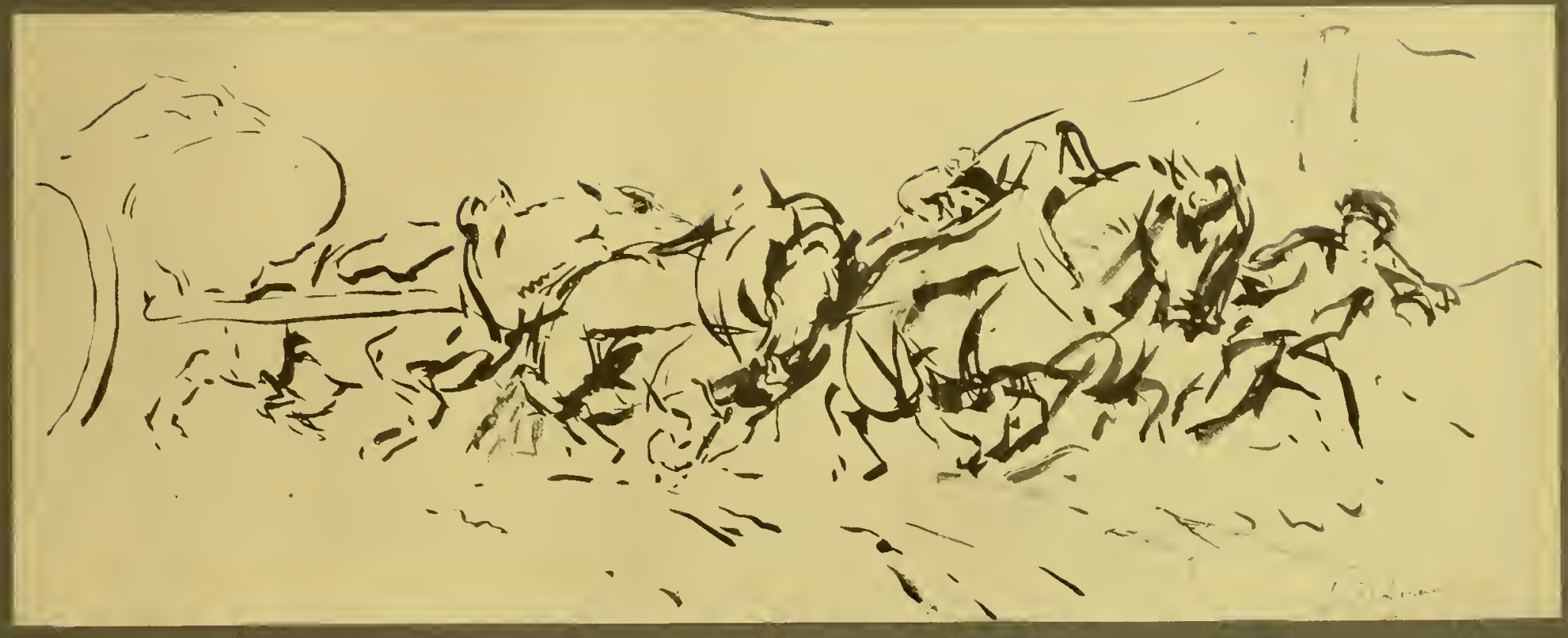





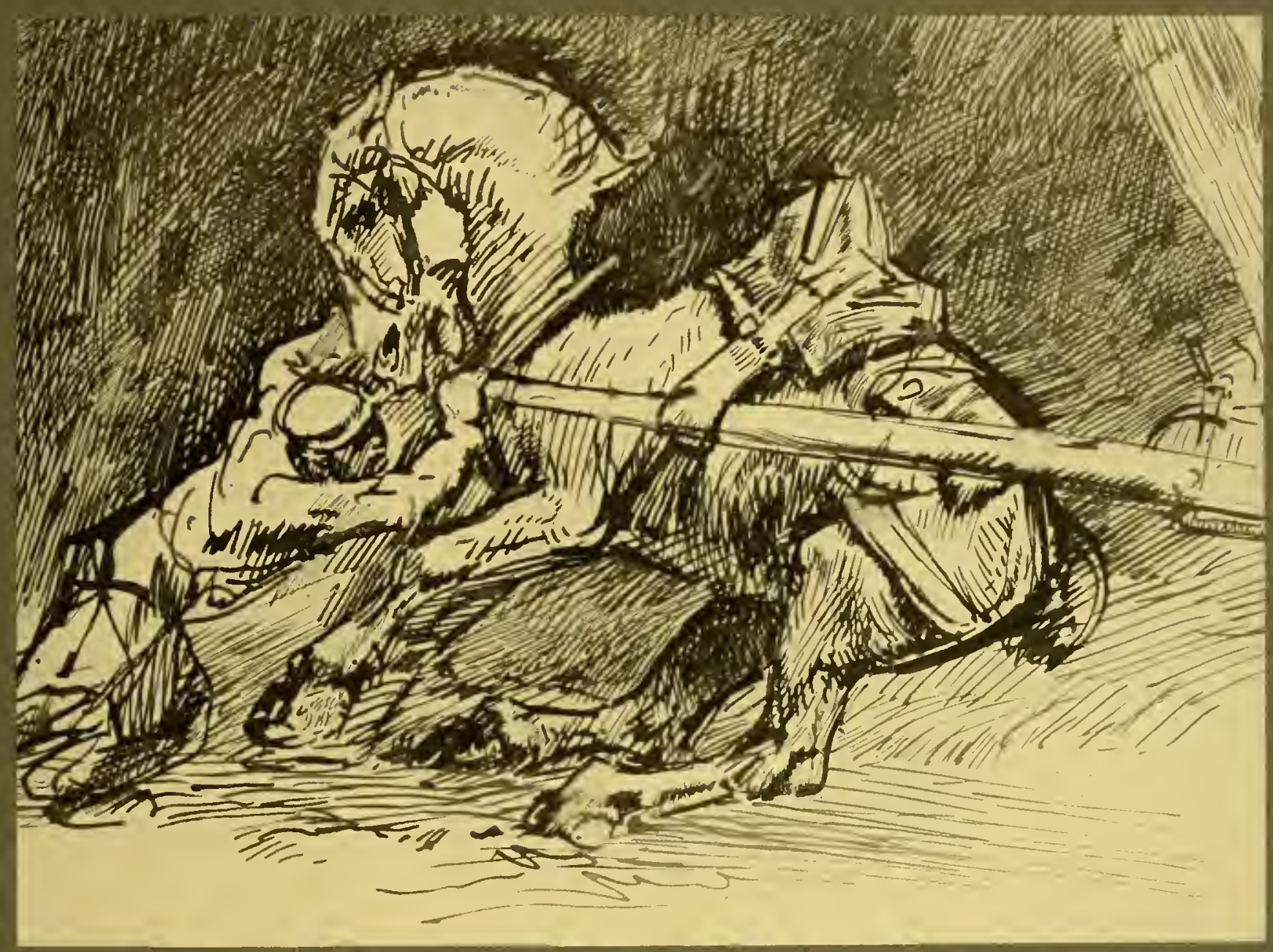

26. BACKING. $\left(7 \frac{3}{8} \times 5 \frac{1}{2}\right)$ 


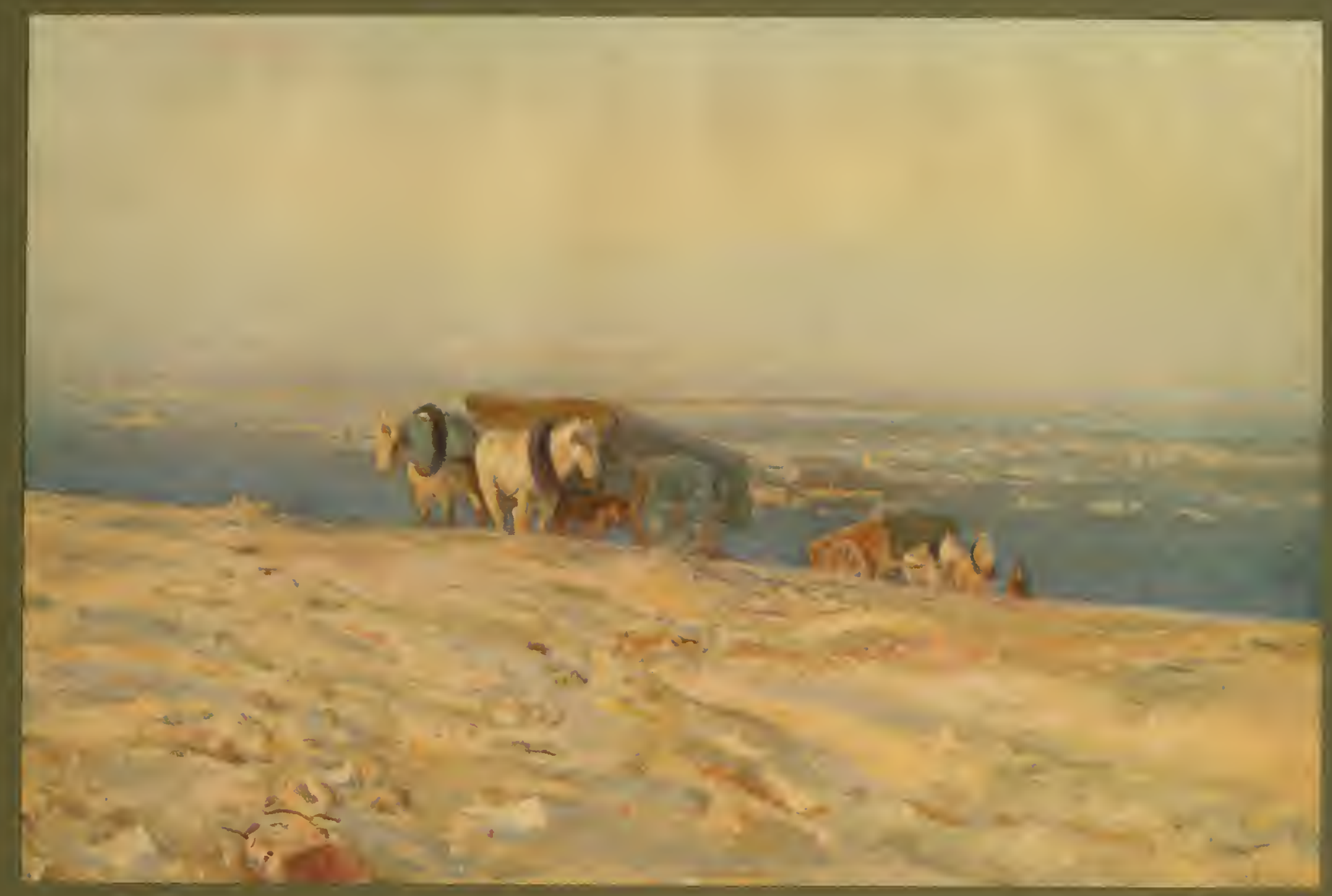

27. ON THE HILL-TOP NEAR PARIS. $(38 \$ \times 26 !)$ 


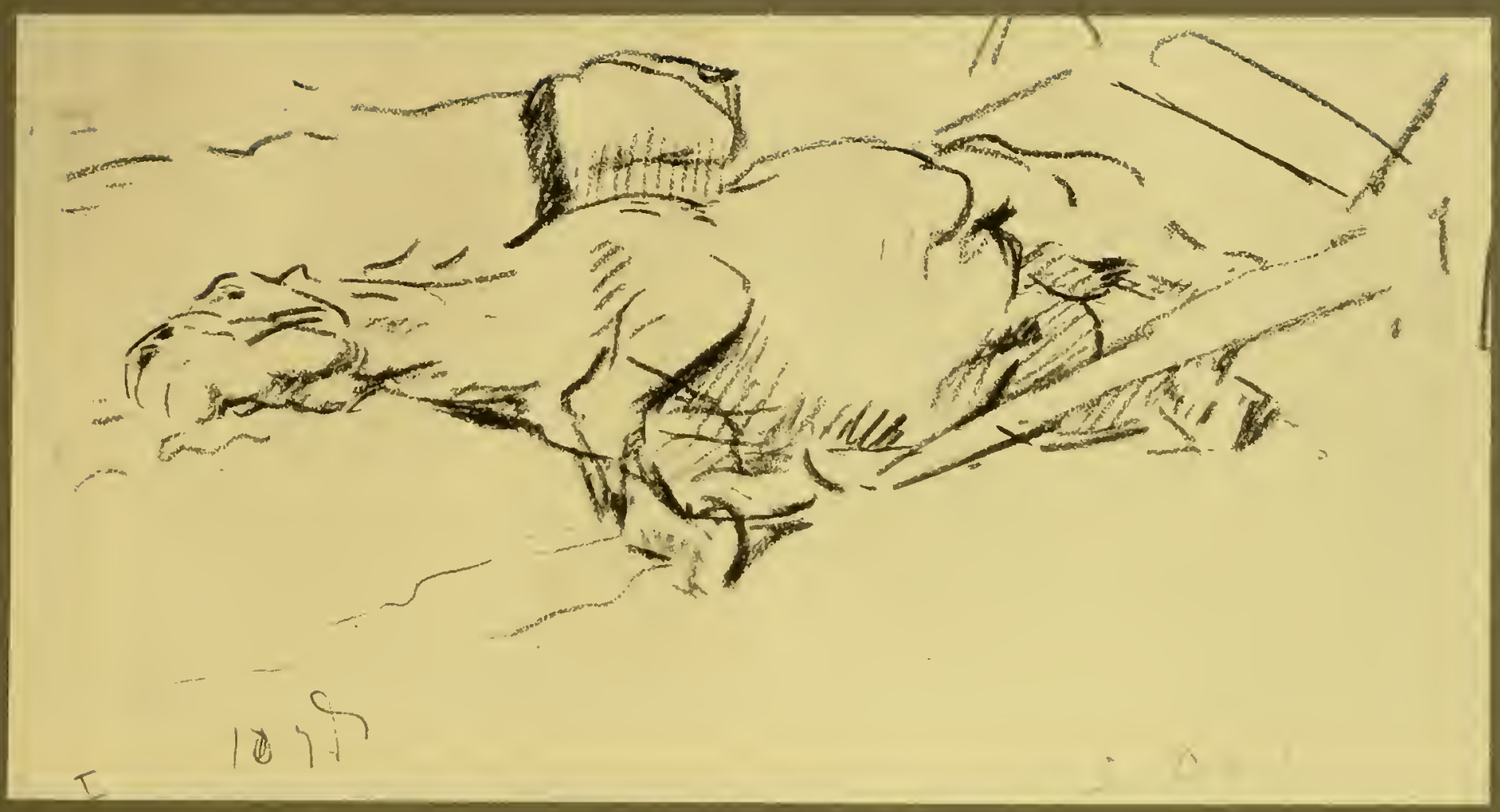

28. FALLEN. $\left(8 \times 4 \frac{1}{2}\right)$ 


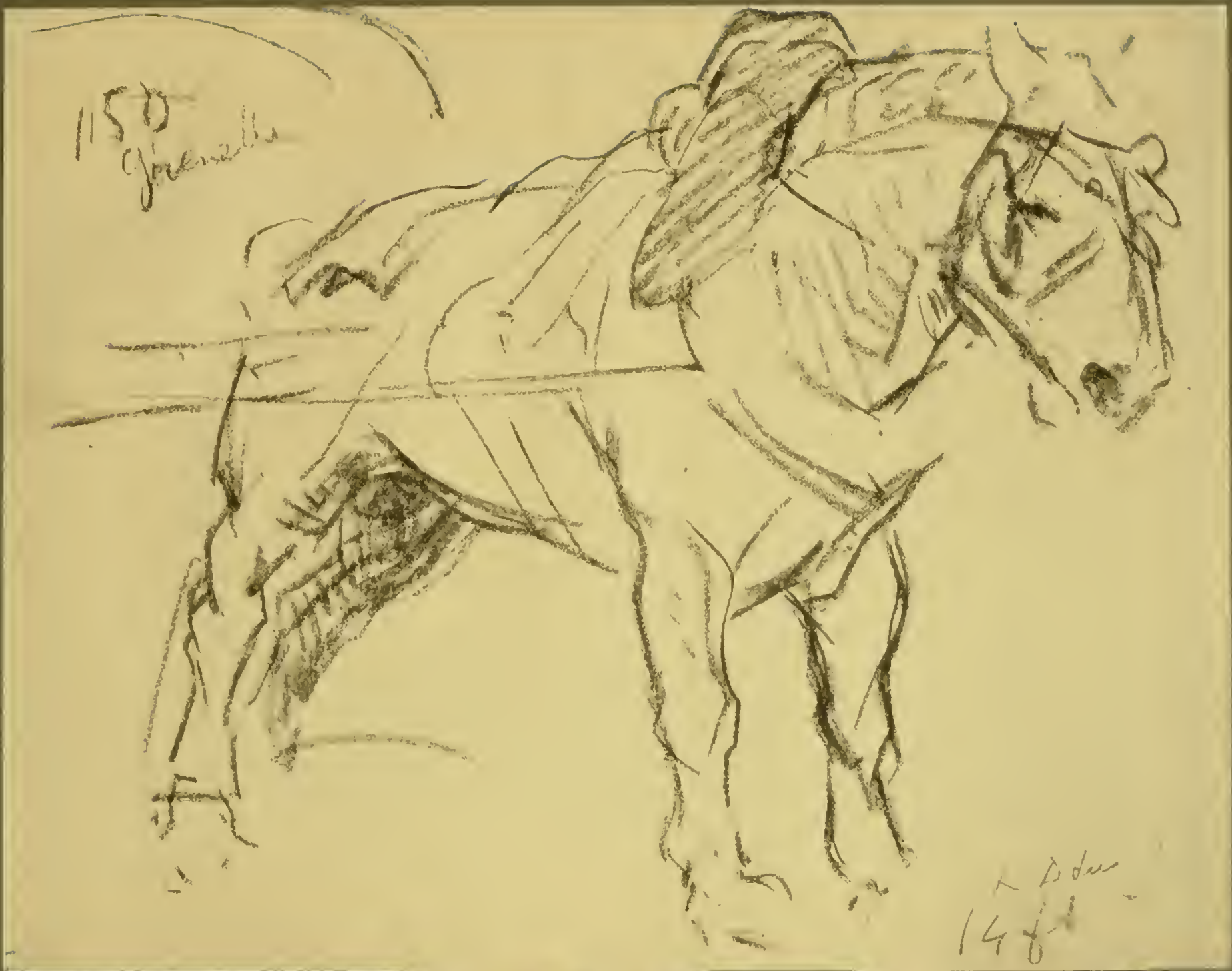

29. BLOWN. $\left(\mathrm{IO} \frac{1}{2} \times 7 \frac{5}{8}\right)$ 


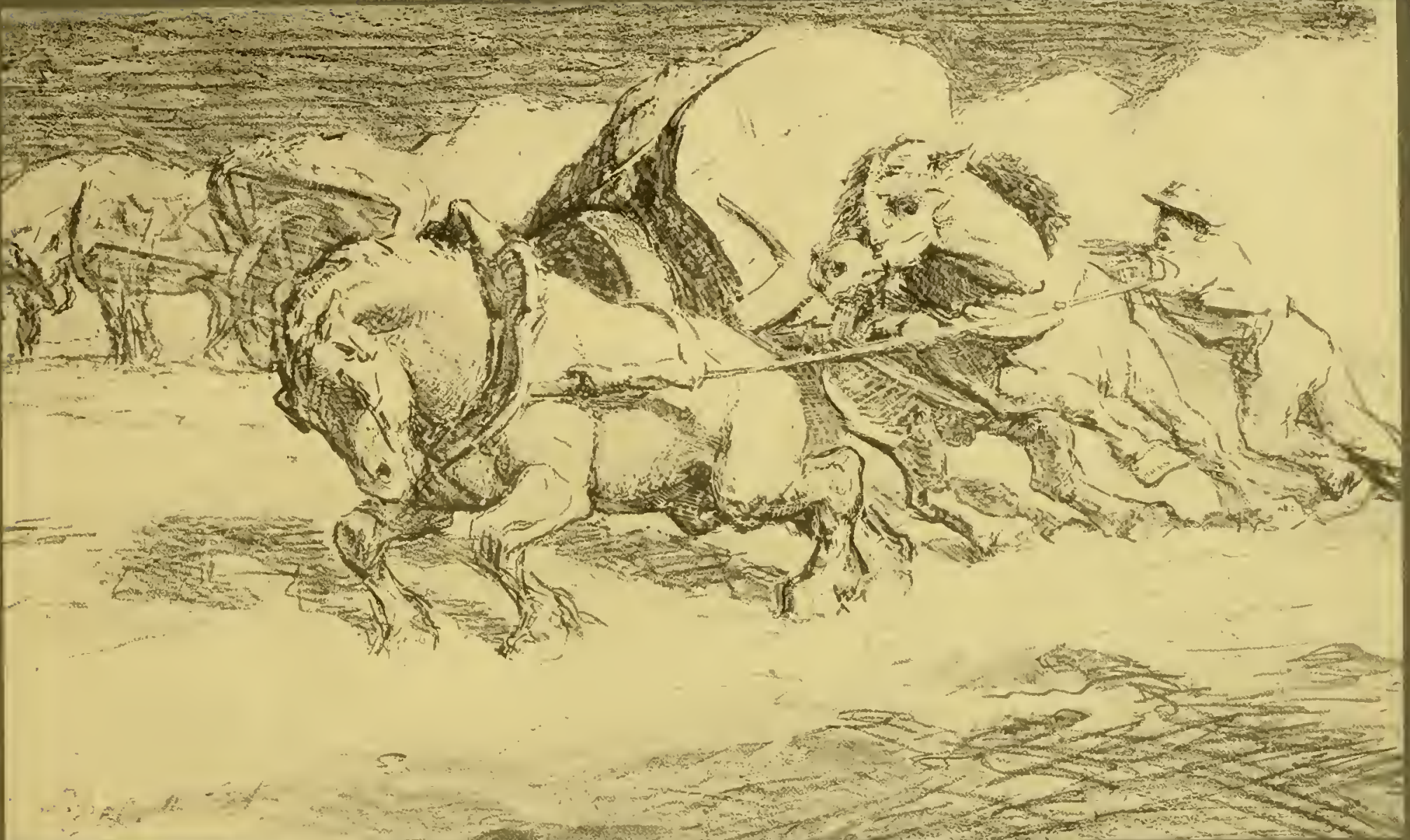

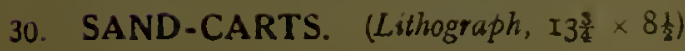




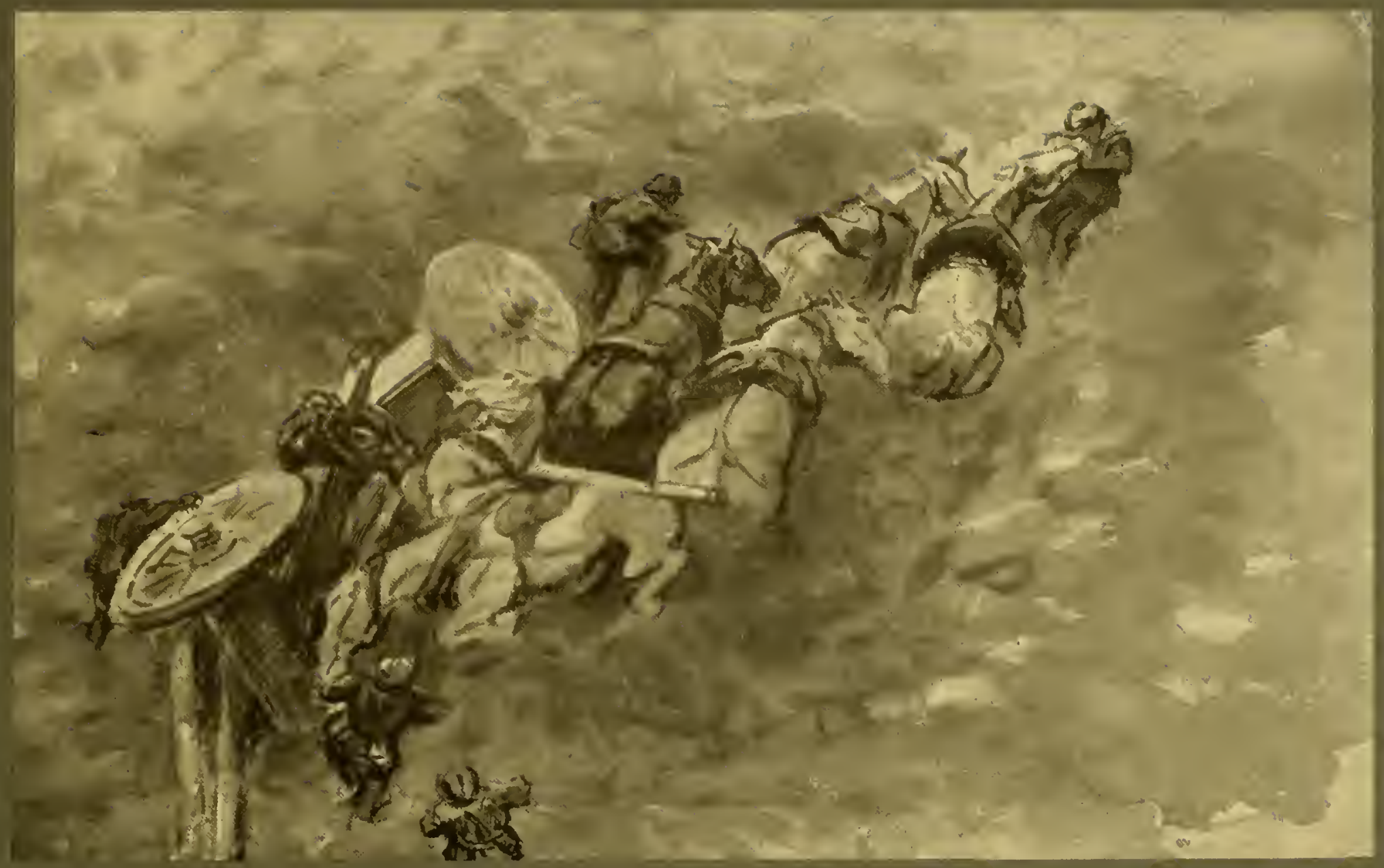

31. GUN-TEAM IN A CRATER. (II $\left.\times 7 \frac{3}{2}\right)$ 


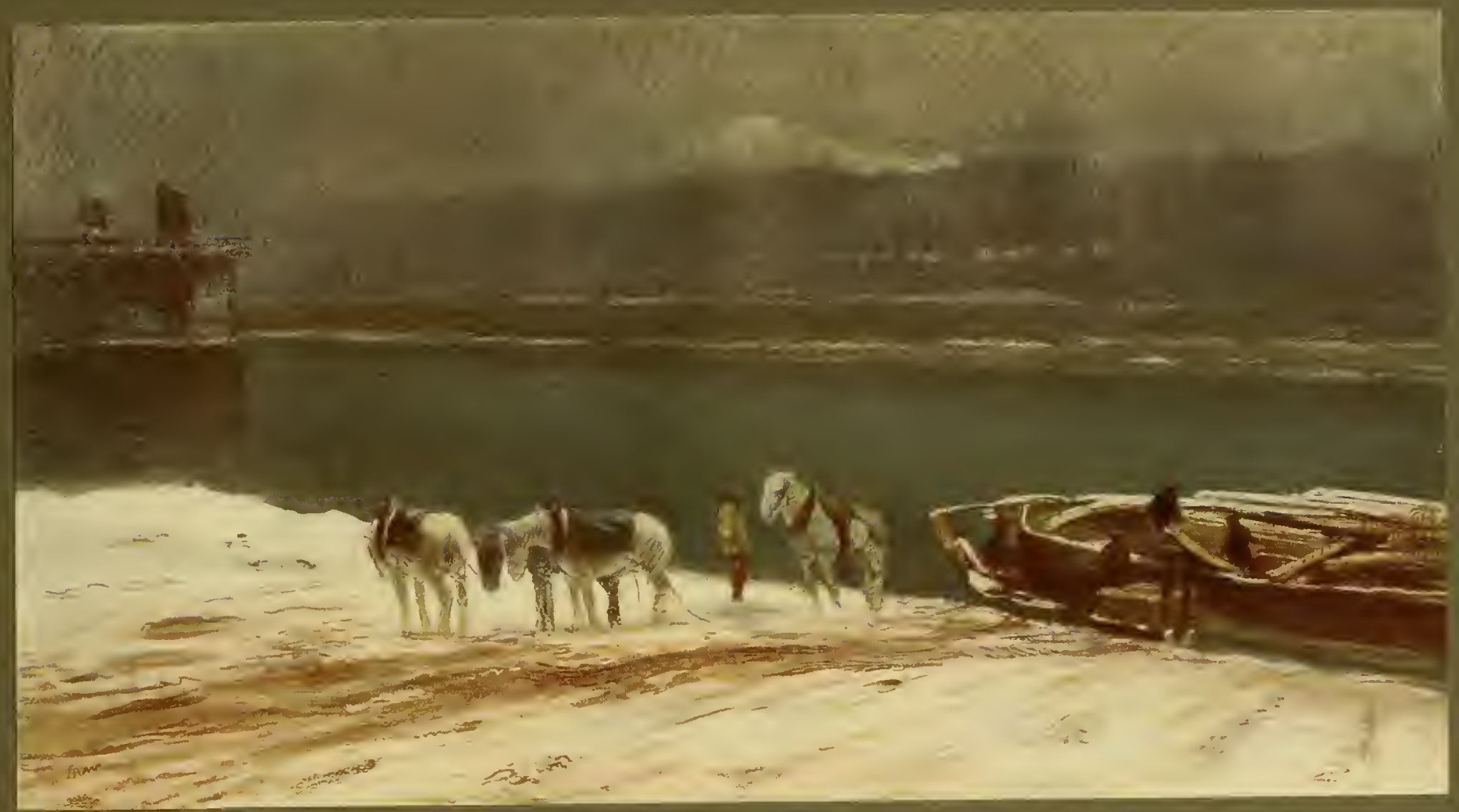

32. THE SEINE: WINTER. $(36 \times 20)$ 
Printed at

Cassell \& Compast, Lisireo

la Belle sauvace, London, EC 


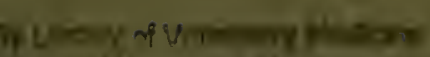

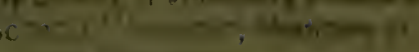

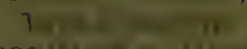

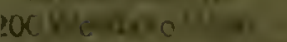

yoxitas $1=8$ 
